\title{
Morphologie comparée des structures céphaliques et génitales des Oxyures du genre Syphacia
}

\author{
par Jean-Claude QUENTIN \\ Laboratoire de Zoologie (Vers), associé au C.N.R.S. (Pr A.-G. Снabaud) \\ Muséum National d'Histoire Na'urelle, 57, rue Cuvier, F.75, Paris, $5^{*}$
}

\section{Résumé}

Les espèces du genre Syphacia sont réparties en dix groupes selon les affinités morphologiques de leurs structures céphaliques. Deux nouvelles espèces sont décrites:

- S. adami n. sp. est parasite d'un Sciuridae africain, Funisciurus pyrrhopus.

$-S$. mesocriceti n. sp. est récolté chez un Cricetidae, Mesocricetus auratus.

- $S$. baylisi Maplestone et Badhuri, 1942, devient synonyme de $S$. muris (Yamaguti, 1935).

Les trois premiers groupes réunissent des Syphacia de Sciuridae.

Chez ces espèces, l'évolution céphalique marquée principalement par une migration latérale des papilles et une dilatation générale du masque facial, s'accompagne chez le mâle de la différenciation des pièces génitales et d'une augmentation du nombre de mamelons cuticulaires ventraux.

Les sept autres rassemblent des Syphacia de Rongeurs Cricetidae, Gerbillidae, Muridae et Microtidae. Chez ces Oxyures il n'existe plus d'évolution parallèle des caractères, mais des spéciations, consécutives de leur large dispersion géographique. 


\section{Summary}

The species of the genus Syphacia are distributed into ten groups according to their morphological similarities and their cephalic structures. Two new species are described:

- S. adami n. sp. is parasiting the african Sciuridae Funisciurus pyrrhopus.

- $S$. mesocriceti n. sp. is occuring in the Cricetidae Mesocricetus auratus.

- S. baylisi Maplestone and Badhuri, 1942, is considered as synonymous of $S$. muris (Yamaguti, 1935).

The first three groups include some Syphacia of Sciuridae. In these species the cephalic evolution is emphasized mainly by a lateral migration of the papillae and a general enlargement of the frontal part of the face, in the male this goes along with the differentiation of genital apparatus and increase of the number of ventral cuticular mamelons.

The last seven groups include the Syphacia from Rodents Cricetidae, Gerbillidae, Muridae and Microtidae. In these Oxyurids a parallel evolution of characters is no longer to be found; only speciation occurs due to their wide geographic distribution.

\section{Introduction}

Le genre Syphacia Seurat, 1916, est classé dans la sous-famille des Oxyurinae (Cobbold, 1864, fam.) et appartient à l'ordre des Ascaridida.

Il regroupe des Oxyures uniquement parasites de Rongeurs Sciuridae, Cricetidae, Gerbillidae, Muridae et Microtidae (1) et présente une très large distribution géographique. Chez beaucoup d'espèces, la morphologie faciale reste inconnue. Tiner, 1948, Tiner et Rausch, 1950, ont remarqué cependant qu'elle variait d'une espèce à l'autre. Ce caractère nous paraît essentiel pour définir les limites spécifiques.

(1) S. obubra Baylis, 1936, parasite d'Anomalurus fraseri (Rongeur Anomaluridae), dont la structure céphalique de la femelle est très particulière, est devenu le type du genre Syphaciuris Schikhobalova, 1951.

S. trichosuri Johnston et Mawson, 1938, parasite de Trichosuris vulpecula Marsupial Phalangeridae et $S$. stossichi (Setti, 1897) parasite d'Hystrix cristata, Rongeur Hystricidae ne sont pas admis dans le genre Syphacia et sont classés comme Oxyuris (sensu lato) par Tiner, 1948, et par Chabaud et Biocca, 1955.

Syphacia srivastavi Sinha, 1960, désigne des Oxyures femelles récoltées dans l'estomac du porc domestique aux Indes. Nous les retirons du genre Syphacia, car l'hôte et les caractères morphologiques de ces Oxyures, la taille des œufs en particulier, $49 \times 27 \mu$, ne correspondent pas au genre Syphacia. Nous les classons comme Oxyuris sensu lato. 
Nous tenterons donc dans ce travail de préciser les structures apicales sur le matériel étudié et de regrouper les espèces entre elles en fonction des ressemblances de leur plateau céphalique et de leur masque facial dont nous donnons les définitions suivantes :

Le plateau céphalique constitue la partie musculaire et parenchymateuse de l'extrémité apicale. Cette région est traversée par la bouche et par les différents filets nerveux qui aboutissent aux papilles et supporte le masque facial.

- Le masque facial représente la région cuticulaire péribuccale qui comprend les lèvres et les terminaisons nerveuses céphaliques. Son contour est légèrement limité par un sillon.

D'autres caractères précisent les limites de chaque espèce ; ce sont :

- la présence ou l'absence de deirides, d'ailes cervicales ou latérales,

- l'ornementation cuticulaire ventrale du mâle,

- les pièces génitales cuticulaires du mâle,

- la longueur et la finesse de l'appendice caudal,

— la taille des œufs.

\section{Matériel étudié}

- Syphacia adami n. sp., ơ et + (ce travail), cæcum, Funisciurus pyrrhopus (Cuvier), Congo.

- Syphacia alata, Quentin, 1969, ठ̋ et $q$, intestin grêle et cæcum, Zygodontomys lasiurus (Lund), Orizomys nigripes (Desmarest), Pernambuco, Brésil, Nectomys alfari (Allen), Colombie.

- S. arctica Tiner et Rausch, 1950, $q$ (dét. Quentin), Dicrostonyx sp., Alaska.

- S. criceti Quentin, 1969, $\delta$ et $\uparrow$, intestin grêle et cæcum d'Oryzomys subflavus (Wagner) et Calomys callosus (Rengger), Pernambuco, Brésil ; cæcum de Kerodon sp., Bolivie.

- S. emileromani Chabaud, Rausch et Desset, 1963, $\delta$ et $q$ paratypes, Apodemus sylvaticus argenteus Tem., Mont Hakkoda, Japon.

- S. eutamii, Tiner, 1948, + (dét. Quentin), Eutamias minimus (Bachm.), envoi du Dr Rausch, Alaska.

- S. frederici Roman, 1945 (dét. Quentin), ơ et + , gros intestin, Apodemus sylvaticus L., La Borie Nouvelle (Hérault) France, Tunisie (dét. J. Bernard).

- S. lophuromyos, Quentin, 1966, ơ et $\$$, cæcum, Lophuromys sikapusi, Tem., République Centrafricaine.

- S. megadeiros, Quentin, 1969, ?, intestin grêle, Rhipidomys latimanus (Tomes) et Orizomys alfaroi (Allen), Colombie.

- S. megaloon, Quentin, 1966, ơ et $\$$, cæcum de Mus minutoides (Smith) et Mus setulosus (Peters), Congo. 
- S. mesocriceti n. sp. (ce travail), + , Mesocricetus auratus (Waterhouse), envoi du Dr Rausch, Artic Health Research.

- S. mon:ana, Yamaguti, 1943 (dét. Chabaud, Rausch et Desset, 1963), ơ et + , Clethrionomys rufocanus subsp. (Sundewall), Ile Rebun, C: r.-bedfordiae (Thomas), Nopporo, Fapon.

- S. muris (Yamaguti, 1935), Yamaguti, 1941 (dét. Quentin), $\delta$ et $q$, cæcum, Rattus norvegicus var. albus; $=$ S. baylisi, Maplestone et Badhuri, 1942 (dét. Roman, 1951), \&, cæcum de Ratius lattus L., St. Didier au Mont-d'Or (Rhône), France.

- S. obvelata (Rud, 1802) dét. Quentin, ơ et $\uparrow$, cæcum de Mus musculus L. var. albus, Paris et + , cæcum de Mus musculus brevirostris. Waterh., Camargue, France.

- S. nigeriana, Baylis, 1928 (dét. Quentin), ở et $\$$, cæcum, Hylomyscus stella (Thomas), Lemniscomys striatus L., Mastomys sp., Praomys jacksoni (de Winton), P. morio (Trouessart), Stochomys longicaudatus (Tullberg), République Centrafricaine.

$\delta$ et $q$, cæcum de Microtus gregalis murici Nelson, Alaska, Microtus oeconomus operarius Nelson, Alaska; M.o. macfarlani Merriam, Alaska; M. p. pennsylvanicus, ord. G.G., Madison, Wisconsin, M. p. drummondi (Aud et Bachm), Winnipeg, Manitoba (Canada); M. mexicanus (Saussure), Mexico. Envoi du Dr R. Rausch, Artic Health Research.

$\uparrow$ cæcum de Microtus arvalis Pall., Arvicola sapidus tenebricus, Miller, 1908, Clethrionomys glareolus (Schreb), Richelieu (Indre-et-Loire), France; = obvelata nigeriana (Baylis, 1928), Bernard, 1963, dét. Bernard, cæcum de Gerbillus campestris (Levaill), Tunisie.

- S. pallaryi (Seurat, 1915), dét. Chabaud, ơ et $\$$, cæcum d'Atlantoxerus getulus (Gessner), Agadir, Maroc.

- S. petrusewiczi, Bernard, 1966, + , cæcum de Clethrionomys glareolus Schr., Mikolajki Mazurie (Pologne), envoi de J. Bernard.

- S. petrusewiczi rauschi, Quentin, 1969, $\uparrow$, cæcum de Clethrionomys rutilus dawsoni (Merriam), Alaska, envoi du Dr R. Rausch, Artic Health Research.

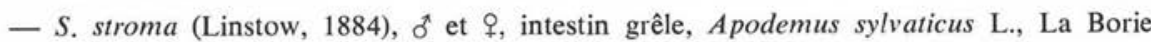
Nouvelle (Hérault), France.

- S. thompsoni Price, 1928 (dét. Quentin), †, Tamiasciurus hudsonicus, Erxleben, Alaska, envoi du Dr R. Rausch.

- S. transafricana, Chabaud et Biocca, 1955, ot et $q$, cæcum de Xerus erythropus (Geoff.), Xerus rutilus (Cretzchm.), Dakar et Somalie.

- S. venteli, Travassos, 1937 (dét. Quentin), ơ et $q$, intestin d'Oryzomys caliginosus (Tomes), Colombie.

\section{Revue des espèces}

Les Syphacia sont regroupés d'après la forme de leur plateau céphalique arrondi ou étiré latéralement, la disposition des papilles submédianes plus ou moins rapprochées des amphides, la présence ou l'absence de lèvres. Dix groupes sont ainsi définis. 


\section{Groupe I :}

Le plateau céphalique est circulaire, les pap.lles céphaliques sont éloignées les unes des autres, sensiblement équidistantes, les lèvres sont absentes ou peu développées (fig. 1).

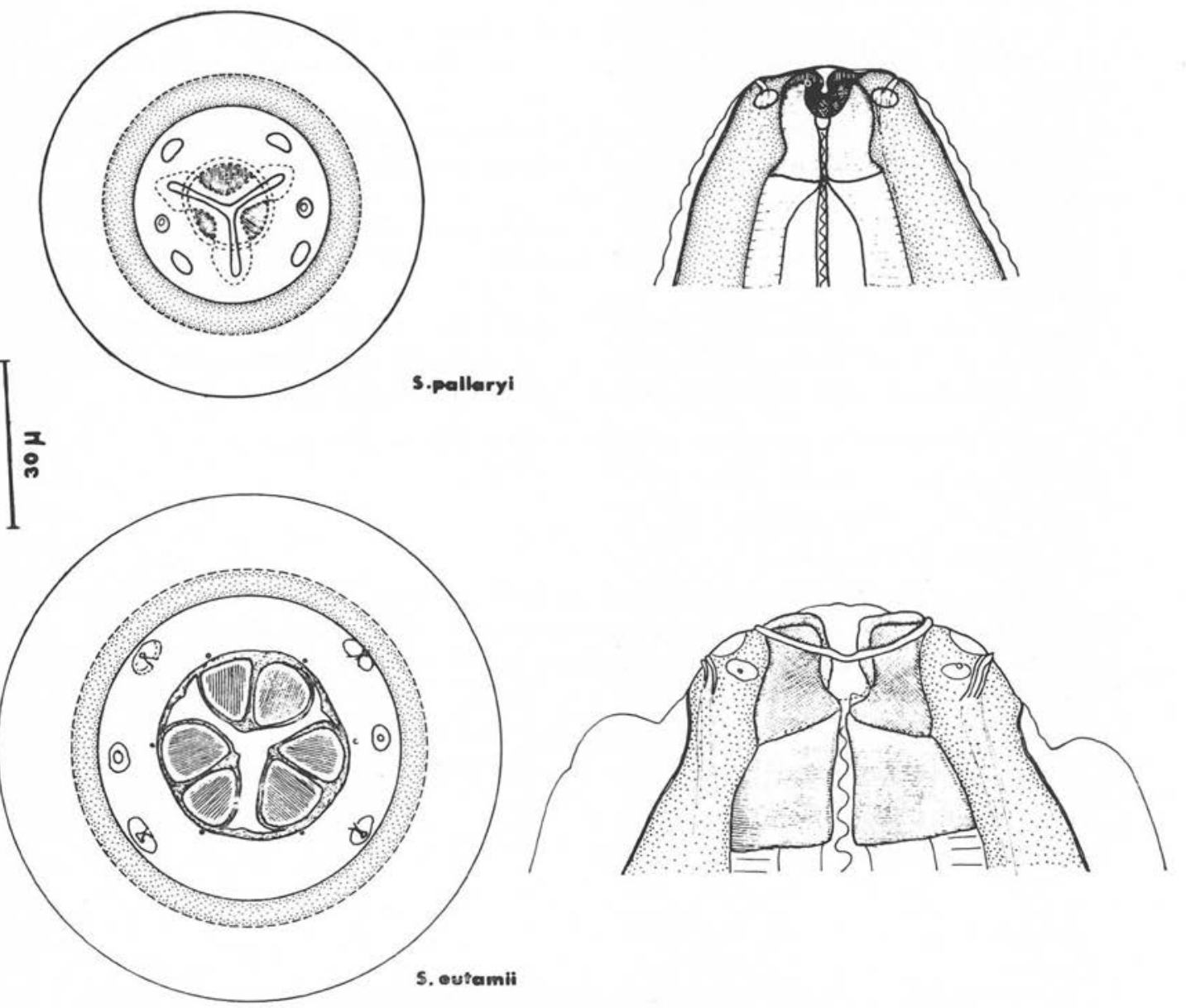

Fig. 1. - Têtes de Syphacia femelles représentées en vue apicale et en vue ventrale. Le cercle externe représente le contour de la vésicule céphalique, le second en pointillé délimite le plateau céphalique, et le cercle interne continu, le bord du masque facial

Ces caractères sont présents chez:

- S. eutamii Tiner, 1948, parasite d'Eutamias minimus Minnesota (U.S.A.),

- S. citelli Tiner et Rausch, 1950, parasite de Citellus armatus et C. variegatus grammarus « Grand Canyon » (U.S.A.), 
- S. pallaryi Seurat, 1915, parasite d'Atlantoxerus getulus (Maroc).

Les caractères céphaliques des deux espèces néarctiques diffèrent selon Tiner très légèrement : "Each of the lips of $S$. eutamii is bisected by a narrow crest on its surface. This is missing from citelli, the lips having an even and convex surface with very slight striations pointing medially. »

L'observation d'un spécimen feme'le de $S$. eutamii (fig. 1) montre qu'il n'existe pas de lèvres, mais trois fortes dents osophagiennes reliées chacune au pourtuur buccal circulaire par une étroite crête.

Le dessin que donne Tiner de $S$. citelli indiquerait également chez cette espèce l'absence de lèvres, l'ouverture buccale béante laissant apparaître trois solides dents œsophagiennes.

Chez S. pallaryi, trois lèvres recouvrent les dents œsophagiennes; les papilles labiales observées chez les deux espèces américaines ne sont pas visibles chez l'espèce marocaine.

Les mâles de ces trois espèces présentent deux bosses circulaires et un court appendice caudal; le crochet du gubernaculum est lisse. Le mâle $S$. pallaryi présente sur la ligne ventrale des perles cuticulaires dans la région moyenne du corps.

Les dimensions du spicule et du gubernaculum sont les suivantes:

S. eutamii : $72-92 \mu$ et $21-26 \mu$.

S. citelli : $78-108 \mu$ et $23-27 \mu$.

S. pallaryi : $84 \mu$ et $55 \mu$.

Chez les femelles, deux ailes latérales naissent en arrière de la vésicule céphalique et s'arrêtent au niveau de l'anus chez $S$. eutamii et $S$. citelli. Chez la femelle de $S$. paliaryi, les deux ailes latérales se forment en arrière du bulbe æsophagien et disparaissent en avant de l'anus.

Les dimensions des œufs sont les suivantes:

S. eutamii : $94-106 \mu \times 35-40 \mu$.

S. citelli : $93-109 \mu$.

S. pallaryi : $84 \mu \times 25 \mu$.

\section{Groupe II :}

Le plateau céphalique est arrondi, les papilles céphaliques dorsales ont migré ventralement par rapport aux commissures interlabiales et se rapprochent latéralement des amphides. La région péribuccale du masque facial est épaissie (fig. 2).

S. transafricana Chabaud et Biocca, 1955 (2), parasite Xerus erythropus (Geoff.) Dakar et Xerus rutilus (Cretzchm) de Somalie.

(2) L'espèce a été étudiée d'après plusieurs paratypes et 1 holotype $q$ de $S$. transafricana. Le dessin donné par Chabaud et Biocca 1955, de l'extrémité céphalique (fig. $1 \mathrm{~A}$, p. 125), où les papilles céphaliques sont localisées loin des amphides, représente en fait une vue de $S$. pallaryi et non pas de $S$. transafricana comme l'indique la légende. 

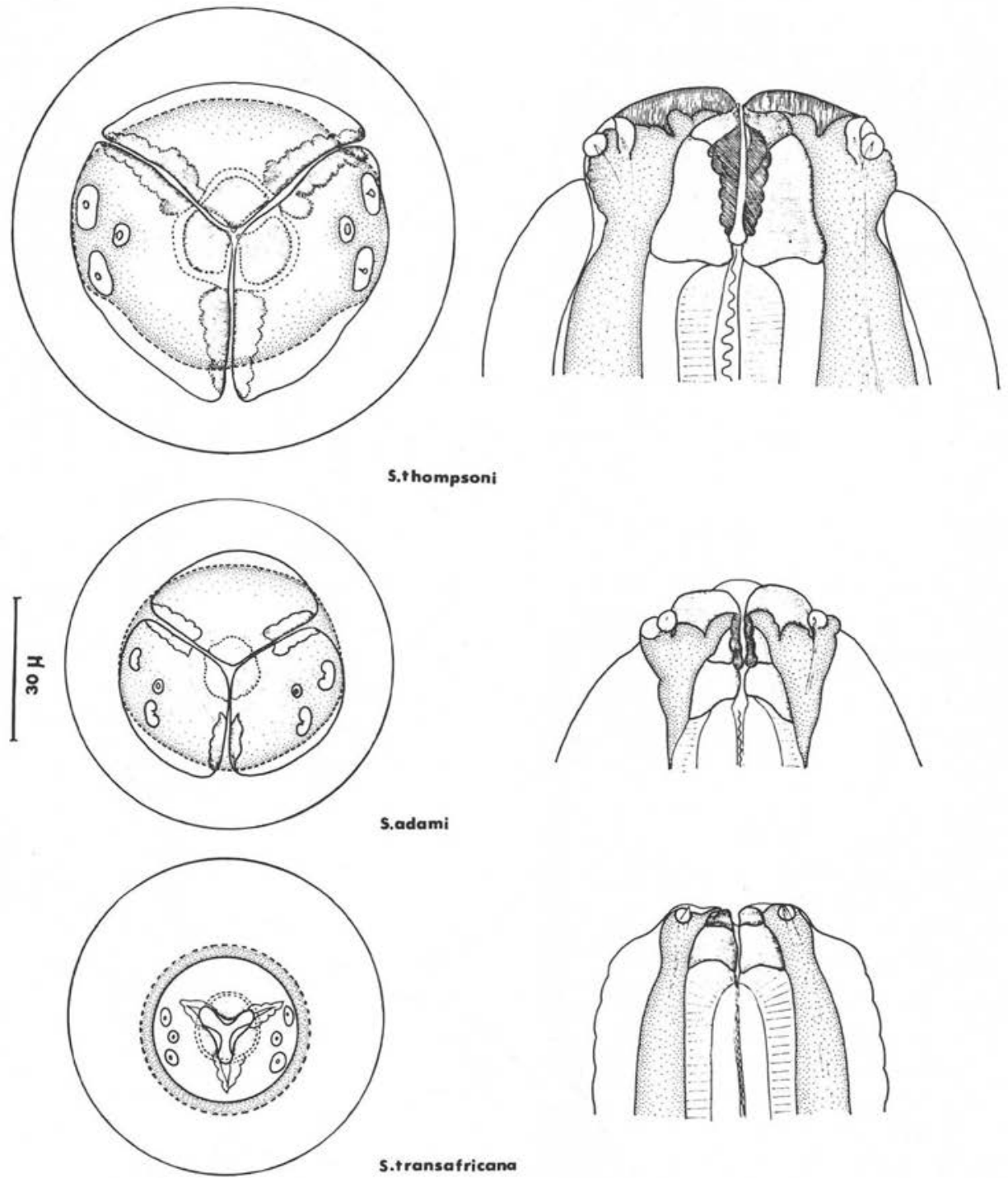

FIG. 2 

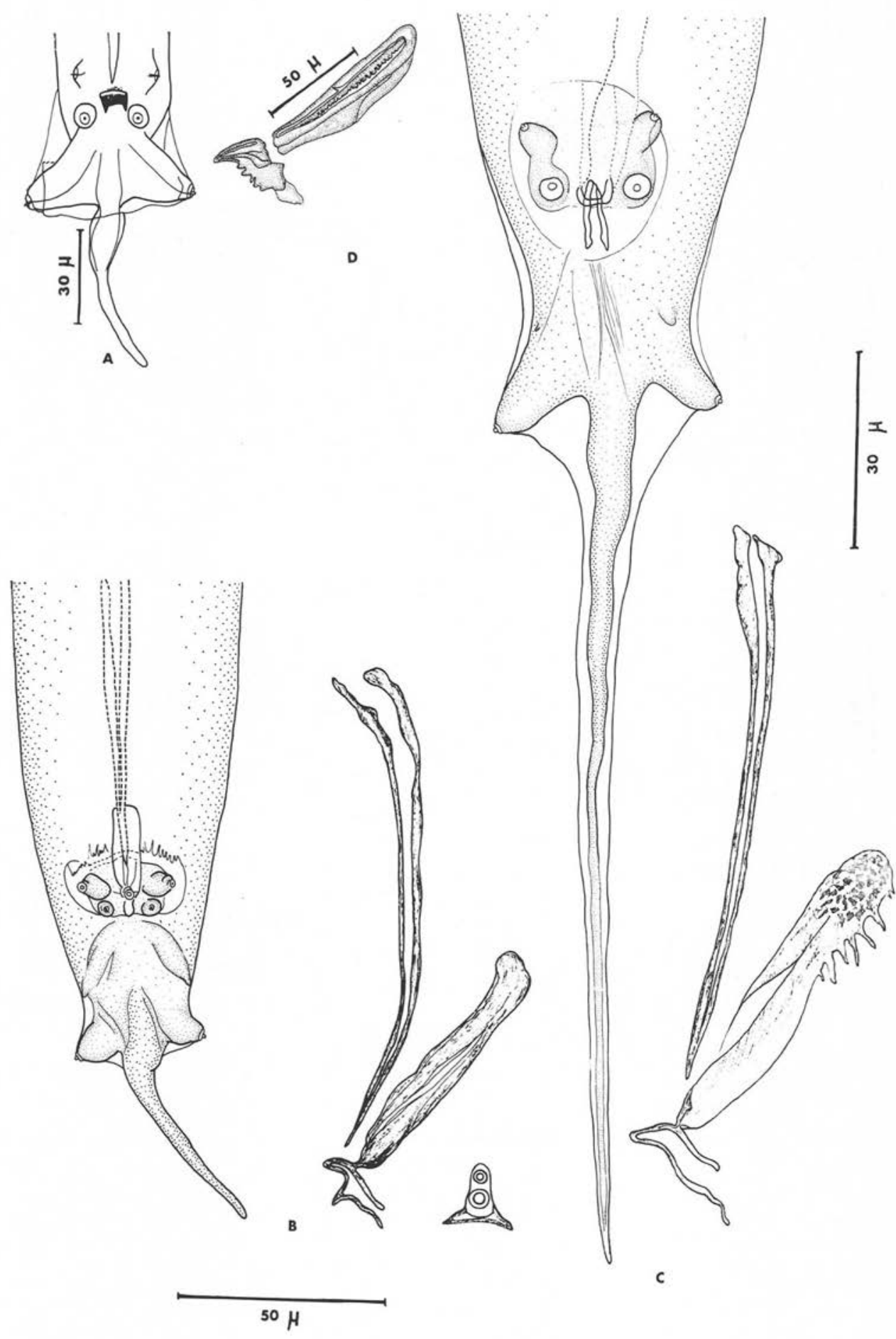
Cette espèce est caractérisée chez le mâle par la présence de deux mamelons cuticulaires, par le crochet du gubernaculum orné d'une dent antérieure, par une pointe caudale plus effilée que celle de $S$. pallaryi ; le spicule mesure $82 \mu$, le gubernaculum $42 \mu$; les ailes latérales ne s'observent que dans la région moyenne du corps chez la femelle.

Les œufs mesurent $85 \mu \times 29 \mu$, et peuvent atteindre $92 \mu$ de long.

\section{Groupe III :}

Le plateau céphalique est circulaire ou légèrement ovalaire. Les papilles céphaliques sont regroupées latéralement avec les amphides. Trois lèvres très dilatées recouvrent totalement le plateau céphalique. Les commissures interlabiales ont leur rebord épaissi (fig. 2).

Ces structures céphaliques sont réunies chez les espèces suivantes :

1. S. thompsoni Price, 1928. Les types sont récoltés dans le caecum du Rongeur Petauristinae: Glaucomys volans volans aux U.S.A. L'espèce est identifiée par Tiner, 1948, chez Glaucomys sabrinus macrostis au Michigan et au Wisconsin, et par Tiner et Rausch, 1949, chez Tamiasciurus hudsonicus en Alaska. Tiner et Rausch, 1950, en précisent la vue apicale. Les mâles ont trois mamelons cuticulaires sur la face ventrale du corps. Le crochet du gubernaculum est denté, la pointe caudale est fine et allongée. Le spicule mesure 156-190 $\mu$, le gubernaculum 95 à $110 \mu$. Ce Syphacia présente en outre deux petites deirides symétriques dans la région antérieure du corps. Chez la femelle, les ailes latérales s'étendent des deirides jusqu'à l'extrémité postérieure. Les œufs mesurent $96-98 \times 28-38 \mu$.

S. thompsoni Price, 1928, sensu Li, 1933, est récolté chez Sciurus vulgaris et Sciurotamias davidianus à Peiping (Chine). La structure céphalique n'est pas précisée.

$\mathrm{Li}$ observe sur le crochet du gubernaculum des projections en forme de pointes comparables à celles décrites dans la description originale de l'espèce. Le spicule mesure sur ses spécimens 210-240 … Le gubernaculum 100 à $130 \mu$. Les dimensions des œufs sont $90-100 \times 30-35 \mu$.

2. Syphacia (Syphacia) adami n. sp. (fig. 4 et 5).

Cet Oxyure a été récolté dans le caecum d'un Ecureuil du Congo en provenance de Brazzaville, le 15 novembre 1969.

FIG. 3. - A - bourse caudale de Syphacia eutamii Tiner, 1948 (d’après Tiner, 1948) B - bourso caudale de $S$. transafricana Chabaud et Biocca, 1955 et détail du spicule du gubernaculum et de son crochet accessoire (ce dernier est représenté en vue latérale et en vue frontale). C - bourse caudale de $S$. adami n. sp. et détail de ses pièces génitales. D - détail du gubernaculum et de son crochet denté de $S$. tjanschani Ablassov, 1956 (d'après Ablassov, 1960).

Les bourses caudales de $S$. transafricana et de $S$. adami sont à l'échelle $50 \mu$, les pièces génitales sont à l'échelle $30 \mu$. 


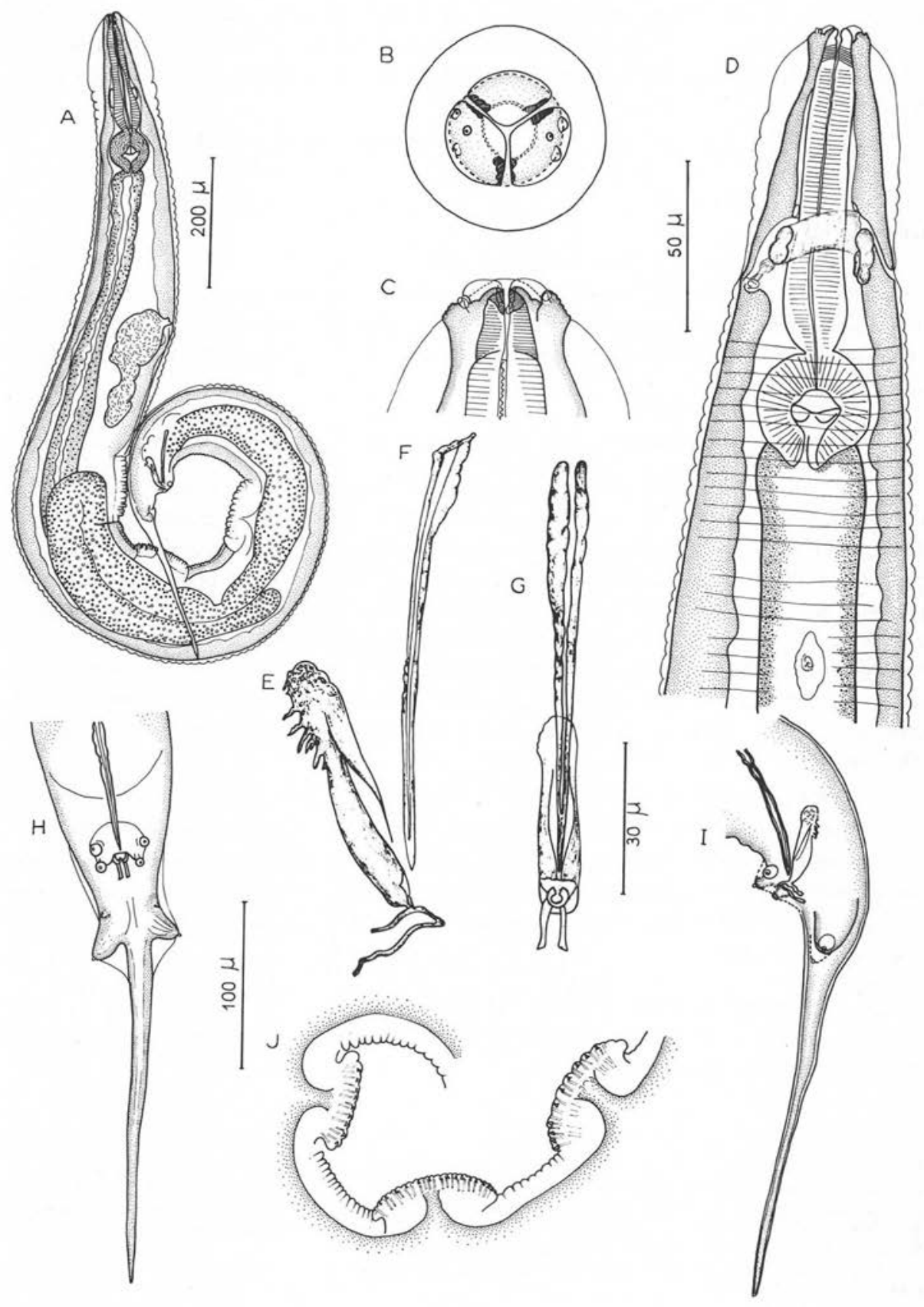


Hôte, matériel étudié : Funisciurus pyrrhopus (Cuvier, 1833); numéro d'autopsie $740 \mathrm{M}$ (types) : $14 \delta+34 q$; numéro d'autopsie $747 \mathrm{M}: 17 \delta+32$ \%

\section{Description :}

Chez le mâle et la femelle, le plateau céphalique est de contour circulaire; le masque facial est divisé en trois énormes lèvres dont les commissures sont épaissies. Chacune des deux lèvres latéro-ventrales porte deux papilles céphaliques très rapprochées et une amphide. Les terminaisons sensorielles sont pédonculées (fig. 5 B). Le cycle interne des papilles n'est pas visible ; l'ouverture buccale est recouverte par la jonction des trois lèvres.

Mâle (fig. 4): Les mâles sont contractés dans leur région caudale. Le mâle holotype mesure $1.950 \mu$ de long, $160 \mu$ de large. La longueur de la vésicule céphalique est de $135 \mu$. L'anneau nerveux, le pore excréteur sont situés respectivement à $130 \mu$ et $500 \mu$ de l'apex. Longueur œsophage + bulbe : $245 \mu$. Bulbe long de $135 \mu$. Longueur de l'intestin : $1.400 \mu$.

Trois bosses cuticulaires ornent la face ventrale du corps; elles débutent loin en arrière du corps à $700 \mu, 850 \mu$ et $1.000 \mu$ de l'apex et mesurent respectivement $95 \mu$, $90 \mu$. et $105 \mu$ de long. Le testicule remonte à $700 \mu$ de l'apex. La description des papilles sur la bourse caudale est précisée sur la figure $4 \mathrm{H}$; chacune des deux phasmides est située sur une des grosses papilles post-anales. Le spicule mesure $84 \mu \times 3 \mu$; le gubernaculum, $52 \mu$. Ce dernier présente une extrémité en massue (fig. $4 \mathrm{E}$ ), l'autre est soudée à un crochet accessoire sans ornementation long de $20 \mu$. La queue mesure $265 \mu$; l'appendice caudal est effilé, long de $205 \mu$.

Femelle: Allotype (fig. 5). Deux très fines ailes latérales naissent en arrière de la vésicule céphalique haute de $180 \mu$. et parcourent le corps jusqu'à l'anus. Les dimensions de cette femelle gravide sont: longueur $3.470 \mu$, largeur $340 \mu$; l'anneau nerveux, le pore excréteur sont situés respectivement à $160 \mu$ et $580 \mu$ de l'apex. Les deirides ne sont pas observées; toutefois, un mince filet nerveux relie leur emplacement présumé à l'anneau nerveux. Le vagin s'ouvre à $820 \mu$ de l'apex. La longueur totale œsophage + bulbe est de $330 \mu$, le diamètre du bulbe est de $80-90 \mu$. Les œufs ne sont pas totalement embryonnés et mesurent $110 \mu \times 34 \mu$. La surface de la coque est percée de nombreux petits pores.

\section{Discussion :}

Les caractères céphaliques de cet Oxyure l'identifient au genre Syphacia, que Cha-

FIg. 4. - Syphacia (Syphacia) adami n. sp. Mâle: A - vue latérale. B - tête, vue apicale le contour externe représente la vésicule céphalique, le pointillé le plateau céphalique, le trait plein les trois lèvres du masque facial. C - tête vue ventrale. D - extrémité antérieure du corps, vue ventrale. E et F - détail du gubernaculum soudé au crochet accessoire et du spicule, vue latérale. G - détail des pièces génitales en vue ventrale. H - bourse caudale vue ventrale. I - idem., vue latérale. $\mathbf{J}$ - détail des trois bosses cuticulaires

A, éch. $200 \mu$. B, C, éch. $50 \mu$. D, H, I, J, éch. $100 \mu . \mathrm{E}, \mathrm{F}, \mathrm{G}$, éch. $30 \mu$ 

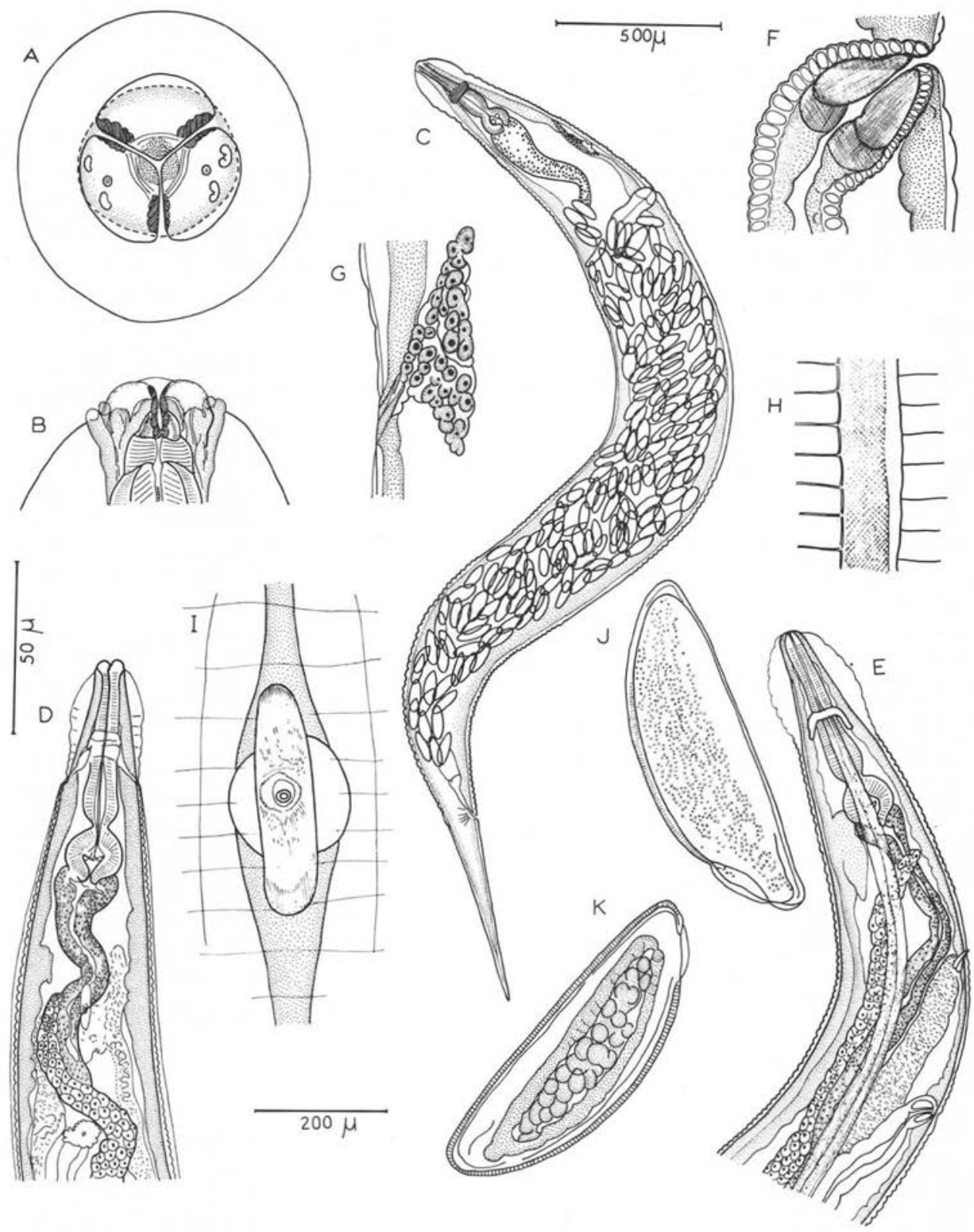

FIG. 5. - Syphacia (Syphacia) adami n. sp. Femelle: A - tête vue apicale. B - vue ventrale. C femelle gravide, vue latérale. D - extrémité antérieure d'une femelle vue ventrale. E - idem, vue latérale. F - vagin. G - filet nerveux reliant l'anneau nerveux à l'emplacement des deirides. H - stries cuticulaires interrompues sur la ligne latérale, l'épaississement du rebord constitue l'aile latérale. I - pore excréteur, vue ventrale. J - détail de la surface d'un œuf. K - embryon A, B, F, G, H, I, J, K, éch. $50 \mu$. C, éch. $500 \mu$. D, E, éch. $200 \mu$ 
baud et Biocca (1955) divisent en deux sous-genres selon le nombre de mamelons cuticulaires ventraux chez le mâle.

- Sous-genre Syphatineria: deux mamelons cuticulaires ornent la face ventrale du corps.

- Sous-genre Syphacia: trois mamelons sont présents.

- Le sous-genre Syphabulea est créé par Gubanov, 1964, pour l'espèce Syphacia sobolevi Gubanov, 1964, dont le mâle possède quatre mamelons cuticulaires ventraux.

Nos spécimens appartiennent au sous-genre Syphacia qui compte actuellement cinq espèces parasites de Sciuridae.

- Syphacia lahorea Alkthar, 1955, est parasite de Funambulus pennanti argentescens du Pakistan. Le mâle possède trois mamelons cuticulaires ventraux; le spicule mesure $126 \mu$, le gubernaculum $63 \mu$; le crochet accessoire n'est pas denté. Ces pièces génitales sont de plus grande taille que celles observées sur notre matériel. Les dimensions des œufs, $90 \times 32 \mu$, sont par contre plus réduites.

- Syphacia coli Schmidt et Kuntz, 1968, est parasite d'Hylopetes nigripes (Thomas), Sciuridae Petauristinae, Philippines. L'espèce est également signalée chez Rattus exulans luteiventris Allen. Les pièces génitales mâles sont plus longues que sur notre matériel ; le spicule mesure 100 à $112 \mu$, le gubernaculum 57-65 $\mu$, et le crochet accessoire, long de 18 à $38 \mu$, est orné de quatre dents triangulaires; il est simple sur nos spécimens. Les œufs mesurent $81-83 \times 25-27 \mu$ et présentent un très grand opercule qui occupe toute la face bombée de l'œuf.

- Syphacia critesi Schmidt et Kuntz, 1968, est parasite d'Hylopetes nigripes et du Rongeur Sciuridae Sundasciurus steerii juvencus aux Philippines. Le spicule mesure $175-195 \mu$, le gubernaculum $75-75 \mu$, le crochet accesoire $25 \mu$. Ce dernier est orné sur chacun des côtés latéraux de sept à huit dents. Les œufs mesurent 71-78 $\times 26-29 \mu$. et possèdent également un très grand opercule sur leur face bombée.

- Syphacia magnispicula Schmidt et Kuntz, 1968, est parasite d'Hylopetes nigripes et de Sunadasciurus steeri juvencus Philippines.

Les pièces génitales sont particulièrement importantes. Le spicule mesure 312 $338 \mu$, le gubernaculum $88-96 \mu$; le crochet accessoire est couvert dans sa partie postérieure de nombreuses petites dents.

L'opercule occupe la face bombée de l'œuf. Celui-ci mesure 71-78 × 26-29 $\mu$.

- Syphacia thompsoni Price, 1928, est parasite de Rongeurs Petauristinae et Sciurinae en région holarctique.

La physionomie céphalique de cet Oxyure (fig. 2) est très proche de nos spécimens. Cependant, la taille du spicule $(156-190 \mu)$, celle du gubernaculum muni d'un crochet denté $(95-110 \mu)$ sont deux fois plus importante que sur notre matériel. Les œufs dont l'opercule très large occupe la face bombée de la coque, sont par contre de plus petites dimensions : $96-98 \mu \times 28-38 \mu$. 
Nous devons donc distinguer nos spécimens des espèces précédemment citées. Nous pensons qu'ils constituent une espèce nouvelle que nous dédions à $\mathrm{J}$. $\mathrm{P}$. Adam qui nous a fait parvenir les Ecureuils parasités. Nous la nommons Syphacia (Syphacia) adami n. sp.

\section{Groupe IV :}

Le plateau céphalique est réduit, de contour ovalaire. Les papilles céphaliques sont rapprochées des amphides latéralement. Les papilles labiales sont bien visibles, au nombre de six. Les lèvres sont inexistantes. La bouche béante découvre trois dents œsophagiennes (fig. 6).

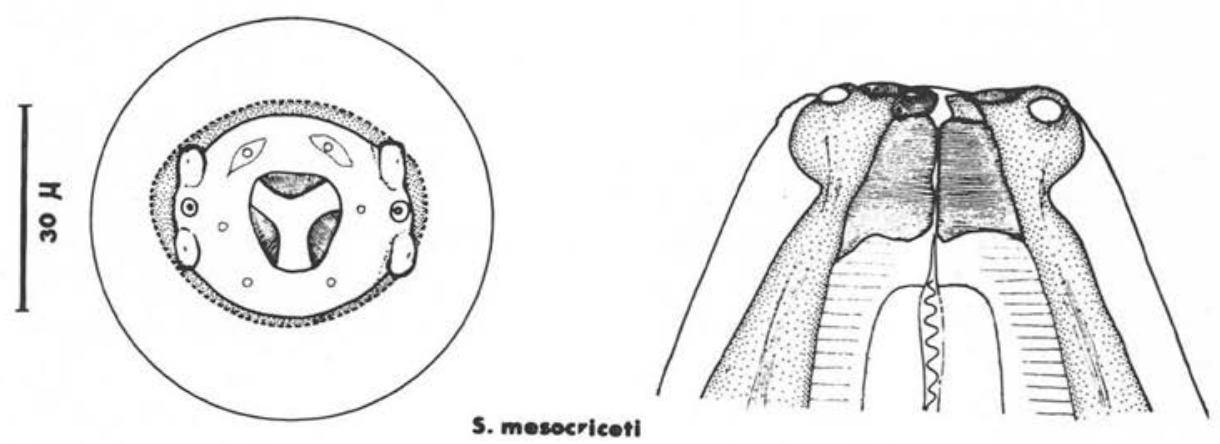

FIG. 6

Une seule espèce: Syphacia mesocriceti $\mathrm{n}$. sp.

Syphacia mesocriceti $\mathrm{n}$. sp.

Cet Oxyure a été récolté à Anchorage, Alaska, le 27 novembre 1953.

Hôte. Matériel étudiée: Mesocricetus auratus (Waterhouse, 1839) (3), 1 \& (type) + 22 \& paratypes.

Description (fig. 7) :

Malgré leur grande taille, les femelles gravides ont une extrémité céphalique étroite.

Ces femelles sont en outre caractérisées par une petite vésicule céphalique haute de $50 \mu$ et par deux ailes latérales. Larges de $16 \mu$ au niveau de l'anneau nerveux, ces ailes s'estompent en arrière du pore excréteur et sont prolongées jusqu'à l'anus par

(3) Mesocricetus auratus ne vit à l'état sauvage qu'en Syrie et en Palestine. En Alaska ce Rongeur est un animal d'élevage. Nous ne connaissons pas, par conséquent, l'origine de ce parasite. 


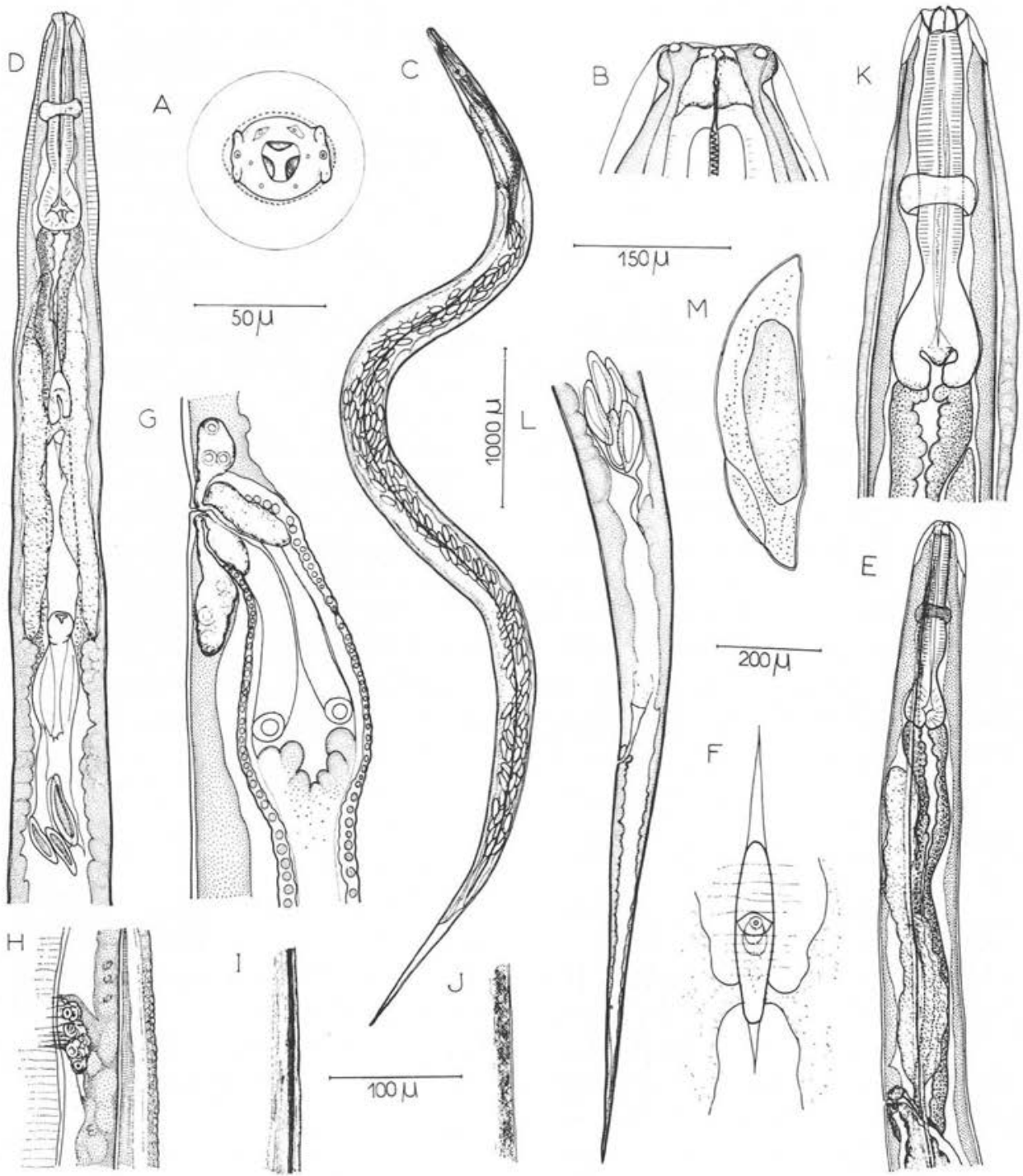

Fig. 7. - Syphacia mesocriceti, n. sp. Femelle: A - tête vue apicale. B - tête vue ventrale. C - femelle vue latérale. D et E - extrémité antérieure du corps en vue ventrale et en vue latérale. F - détail du pore excréteur. G - ovéjecteur, vue latérale. H - détail de l'aile latérale au niveau de l'anneau nerveux, vue ventrale. I - aile latérale niveau du vagin, vue latérale. J - idem, région moyenne du corps. K - région œsophagienne, vue ventrale. L - extrémité caudale de la femelle. M - œuf A, B, F, G, I, J, M, éch. $50 \mu$. C, éch. $1000 \mu$ D, E, L, éch. $200 \mu . \mathrm{K}$, éch. $150 \mu$ 
deux minces replis cuticulaires latéraux (fig. $7 \mathrm{H}, \mathrm{I}, \mathrm{J}$ ). La femelle holotype présente les dimensions suivantes: longueur $7.400 \mu$, largeur $300 \mu$. L'anneau nerveux et le pore excréteur sont respectivement situés à $175 \mu$ et $720 \mu$ de l'apex. Longueur œsophage + bulbe : $390 \mu$; dimensions du bulbe : $120 \times 85 \mu$. Le vagin s'ouvre à $1.115 \mu$ de l'apex. Les œufs mesurent de $125 \mu$ à $128 \mu$ de long sur $30 \mu$ à $35 \mu$ de large. La longueur de la queue est de $760 ;.$

\section{Discussion :}

En l'absence de mâle, les caractères céphaliques: papilles submédianes et amphides regroupées latéralement, bouche triangulaire sans interlabia, permettent de classer cet Oxyure dans le genre Syphacia.

Sa physionomie céphalique s'apparente seulement par la réduction de son masque tacial à l'espèce $S$. transafricana Chabaud et Biocca, 1955, parasite de Sciurinae Xerus erythropus (Geoff.) et Xerus rutilus (Cretzchm.), de Dakar et de Somalie (fig. 2).

Les commissures interlabiales sont cependant marquées chez $S$. transafricana, et. pour une surface voisine du plateau céphalique, les femelles sont de plus petite taille $(3 \mathrm{~mm})$. Les œufs de $S$. transafricana mesurent $85-92 \times 28 \mu$, contre $125-128 \times 38 \mu$ chez les femelles de Syphacia parasites de Mesocricetus auratus.

Nous considérons donc que ces femelles appartiennent à une espèce distincte des autres espèces congénères. Nous pensons qu'elle est nouvelle et la nommons Syphacia mesocriceti $\mathrm{n}$. sp.

\section{Groupe V :}

Le contour du plateau céphalique est d'un ovale régulier. Le masque facial est délimité latéralement par les papilles submédianes. La région péribuccale est constituée de trois lèvres dont le dessin et l'épaisseur sont plus ou moins marqués selon les espèces. Les ailes cervicales sont absentes. Il existe deux ailes latérales.

Ce groupe doit être subdivisé en quatre parties selon la taille du plateau céphalique, indiqué par l'écartement des pores amphidiaux mesuré sur les femelles gravides, par le dessin des lèvres et leur épaisseur.

1. Le plateau céphalique est réduit; la distance séparant les pores amphidiaux est de 30 à $40 \mu$; les lèvres sont présentes (fig. 8).

Cette structure est observée chez des Syphacia de Rongeurs de Centrafrique: Hylomyscus stella, Lemniscomys striatus, Mastomys sp., Praomys jacksoni, P. morio et Stochomys longicaudatus.

Nous identifions ces Oxyures à l'espèce $S$. nigeriana Baylis, 1928, récoltés chez certains de ces Muridae dans la même région géographique. La même structure caractérise aussi des Syphacia parasites de Gerbillus campestris en Tunisie, et ceux récoltés 

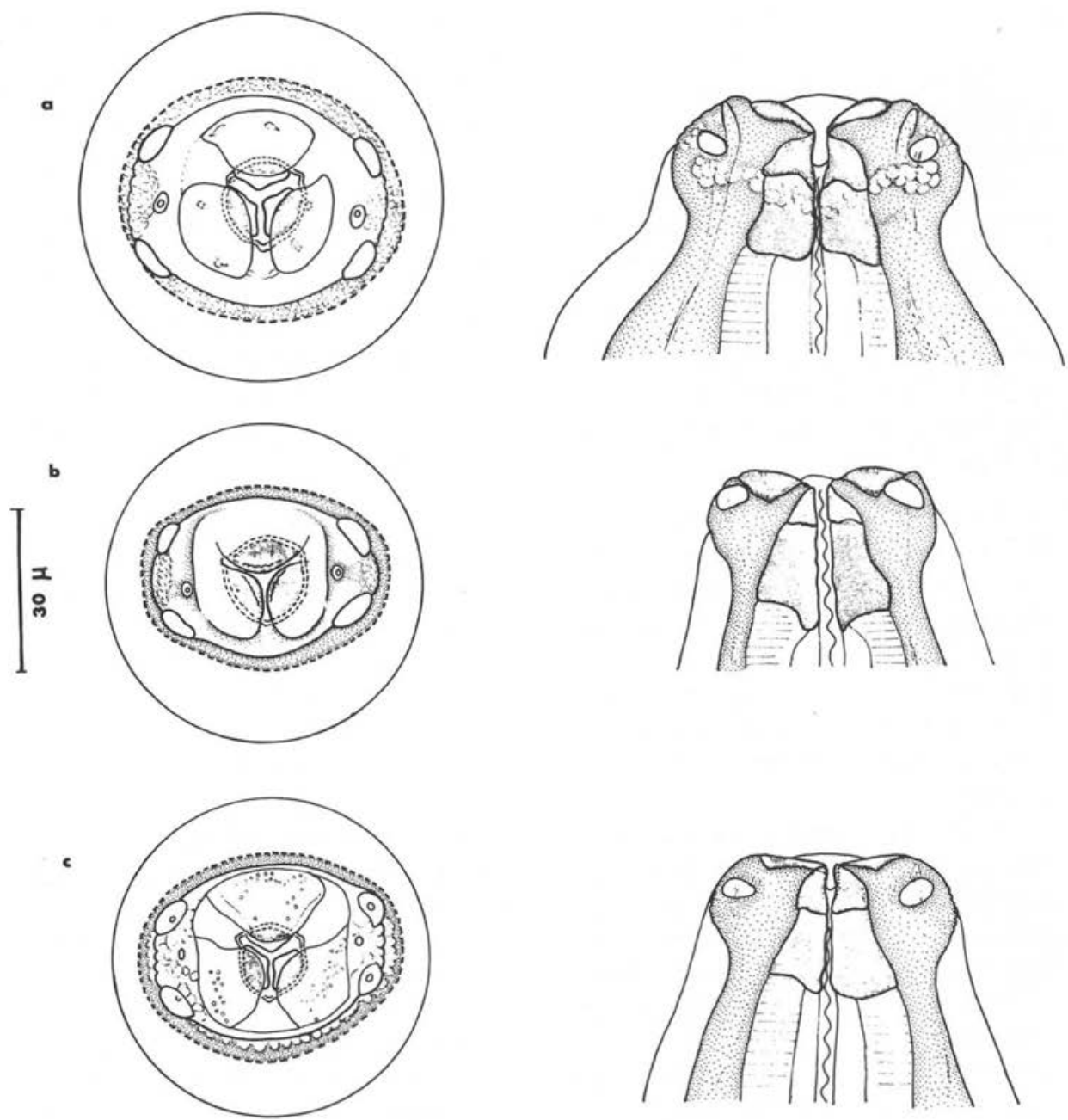

S. nigeriana

Fig. 8. - Structures céphaliques de Syphacia nigeriana observées chez des femelles gravides parasites a) de Lemniscomys striatus (République Centrafricaine).

b) de Praomys jacksoni (République Centrafricaine).

c) de Microtus gregalis (Alaska).

au niveau du caecum de Microtidae holarctiques appartenant aux espèces suivantes: Microtus gregalis murici Alaska; $M$. oeconomus operarius Alaska; $M$. o. macfarlani Alaska; $M$. pensylvanicus alcorni Alaska ; $M$. p. pennsylvanicus Madison, Wisconsin ; M. p. drummondi Winnipeg, Manitoba (Canada); M. mexicanus mexicanus Mexico; 
Microtus arvalis, Arvicola sapidus tenebricus et Clethrionomys glareolus, piégés à Richelieu (Indre-et-Loire), France.

Les autres caractères correspondent. Les dimensions du spicule du gubernaculum. et des œufs des Syphacia de Muridae africains sont respectivement de 70-85 $\mu, 35-38 \mu$ et $75-95 \times 30-35 \mu$.

Le spicule mesure $95 \mu$, le gubernaculum $35 \mu$, et les œufs $113-125 \times 35-40 \mu$ sur les types de $S$. nigeriana Baylis, 1928. Chez les Syphacia de Microtidae, le spicule est long de 75-80 $\mu$; un gubernaculum mesure $37 \mu$ et la taille des œufs est de 92-116 $\times 35-51 \mu$ (fig. 9).

En conséquence, nous pensons que les Syphacia de Microtidae holarctiques, qui présentent des structures céphaliques et génitales morphologiquement identiques à celles des Syphacia de Gerbillidae et de Muridae africaıns, appartiennent à la même espèce, Syphacia nigeriana. Celle-ci, d'ailleurs, a été signalée chez des Microtidae en Allemagne par Stammer, 1955.

2. Le plateau céphalique est de grande taille. L'écart des pores amphidiaux est de $45 \mu$ à $50 \mu$. Les lèvres ne sont pas délimitées (fig. 10).

Cette structure caractérise l'espèce $S$. obvelata (Rudolphi, 1802). Les types sont récoltés par Rudolphi (1800) au niveau du gros intestin de la Souris domestique : « Ich hingegen saud der 13 ten november 1800 gegen vierzig springwürmer inner colon (nahe brem Blinddarm) einer männlichen Maus... »

Bernard, 1963, indique que les diverses mensurations correspondent chez $S$. obvelata et $S$. nigeriana et que les crêtes cuticulaires latérales des femelles sont absolument semblables.

Nous pensons cependant que ces deux espèces peuvent être distinguées, car elles diflèrent légèrement par leur surface céphalique et par leur dessin facial. En outre, Bernard signale une différence entre les deux espèces dans la membrane bordant l'appendice caudal du mâle. Cette membrane se prolonge jusqu'à l'extrémité de la queue chez $S$. obvelata; elle n'atteint pas l'extrémité de l'appendice caudal chez $S$. nigeriana.

Nous ne pensons pas devoir attribuer de valeur spécifique aux histogrammes. Nous avons en effet constaté, sur 50 femelles de $S$. obvelata parasites de la Souris blanche et 50 femelles parasites de Mus musculus brevirostris de Camargue, que le polygone de fréquence établi d'après les rapports longueur totale du corps sur longueur de l'œsophage présentait un pic à la fréquence 12-14. Roman (1951) obtient, sur 50 femelles de $S$. obvelata parasites de la Souris grise, un sommet à la fréquence 16-18.

Fig. 9. - Bourses caudales et pièces génitales mâle de Syphacia du groupe V

A - S. nigeriana, hôte Microtus oeconomus (Alaska).

B - S. nigeriana, hôte Stochomys longicaudatus (Centrafrique).

C - S. obvelata, hôte Mus musculus (France).

D - S. arctica, hôte Dicrostonyx (Alaska).

E - S. venteli, hôte Oryzomys caliginosus (Colombie).

Les bourses caudales sont à l'échelle $50 \mu$. Les pièces génitales sont à l'échelle $30 \mu$. Ces échelles sont adoptées pour les structures génitales des autres espèces de Syphacia 


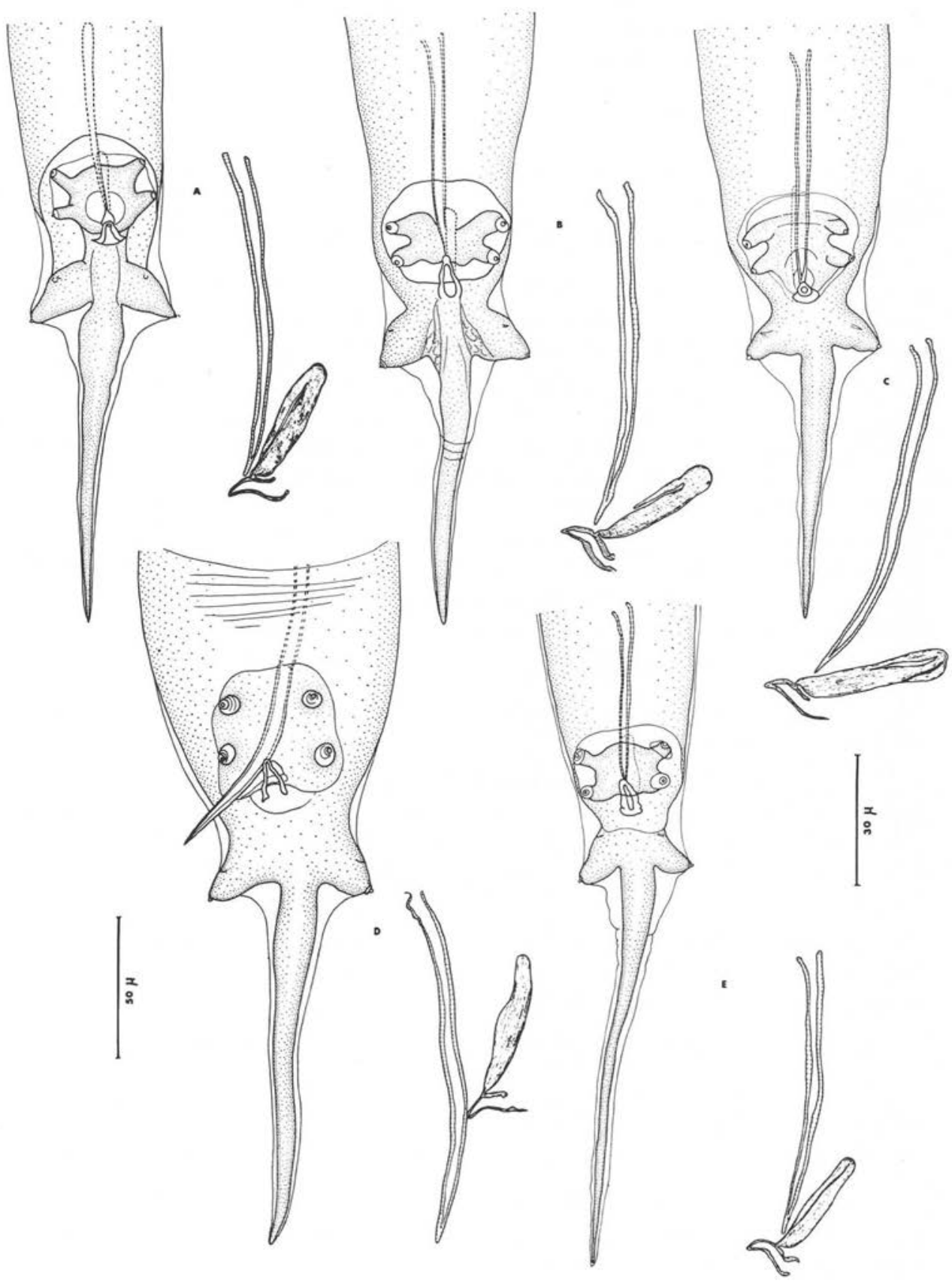


Ces rapports biométriques varient donc selon les populations d'Oxyures chez une même espèce, et nous pensons par conséquent qu'ils ne constituent pas un caractère susceptible de séparer les espèces entre elles.

D'après Roman, 1951 :

- Le spicule de $S$. obvelata mesure : 68-90 $\mu$.

- Le gubernaculum: 28-34 u.

- Les dimensions des œufs sont : 118-153 $\times 33-54,5 \mu$.

3. Le plateau céphalique est de grande taille, entouré d'un collier de fines bosse,lures cuticulaires. L'écart des pores amphidiaux est de $45 \mu$ à $50 \mu$. Les lèvres sont (particulièrement marquées sur le masque facial (fig. 11).

L'allongement cóphalique dans le sens latéral et le dessin des lèvres ont déjà été remarqués par Chabaud, Rausch et Desset, 1963, pour caractériser l'espèce Syphacia montana Yamaguti, 1943, parasite de Clethrionomys rufocanus sub. sp. et C. $r$. bedfordiae Thomas au Japon. Les types ont été récoltés au Japon chez Clethrionomys rufocanus smithii Thomas et chez Microtus montebelli (Milne Edwards) à Miura (Kiso). (La synonymie des sous-espèces smithii et bedfordiae est admise par certains auteurs). Le spicule est long, de $80-90 \mu$ ( $81-87 \mu$ sur les spécimens types). Les ailes latérales sont présentes mais extrêmement réduites. Les dimensions des œufs sont $110 \mu \times 32 \mu$ (Chabaud et coll., 1963), 108-125 $. \times 29-40 \mu$ (Yamaguti, 1943).

Syphacia arctica Tiner et Rausch, 1950.

Les types de cette espèce sont récoltés chez Dicrostonyx groenlandicus ribricatus (Richardson) Alaska.

Des spécimens femelles et un mâle récoltés chez un Dicrostonyx d'Alaska correspondent par leurs dimensions et leur morphologie à la description originale de Tiner et Rausch. La physionomie apicale de cet Oxyure est identique par le dessin des lèvres, celui de sa collerette de bosselures cuticulaires et par sa taille, à l'espèce $S$. montana Yamaguti, 1943.

Les autres caractères cuticulaires et génitaux correspondent entre les deux espèces, et le contour rectangulaire de la plaque tégumentaire vésicale remarquée par Chabaud et coll. chez $S$. montana est présent chez $S$. arctica.

Le spicule de $S$. arctica mesure 80-94 $\mu$ de long, le gubernaculum 33-48 $\mu$.

Les ailes latérales sont aussi extrêmement réduites. Seule la morphologie et la taille des œufs permettent de séparer les deux espèces.

Ils mesurent $91-96 \mu \times 38-39 \mu$ chez $S$. arctica et $110 \mu \times 32 \mu$ chez $S$. montana.

4. La taille du plateau céphalique et l'écart des pores amphidiaux correspondent aux dimensions de $S$. nigeriana, mais les lèvres très dilatées débordent dorsalement et ventralement le plateau céphalique (fig. 12). 


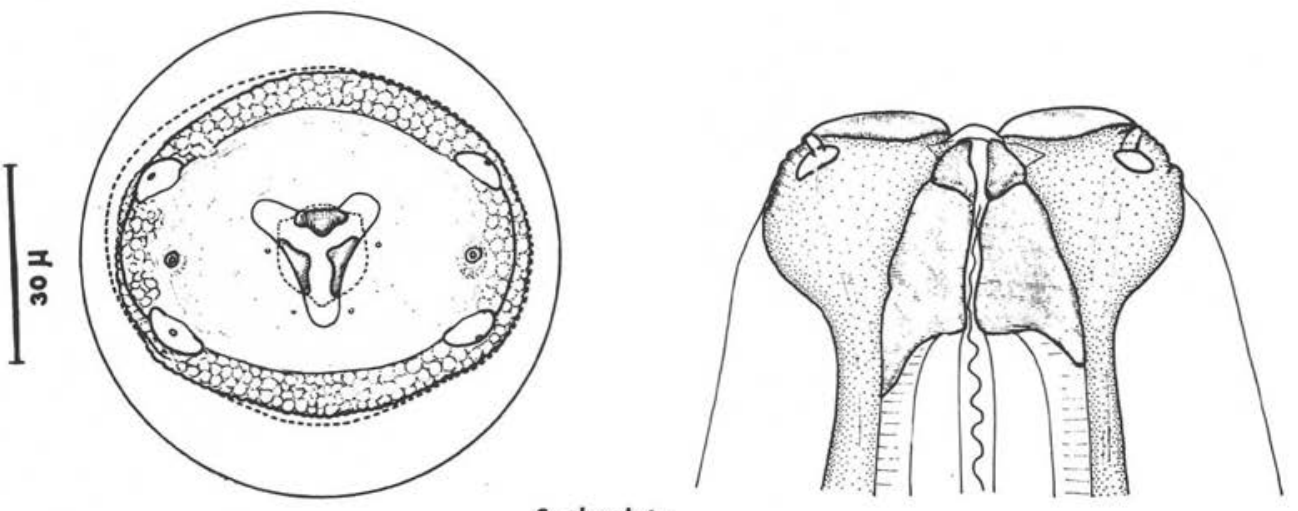

FIG. 10

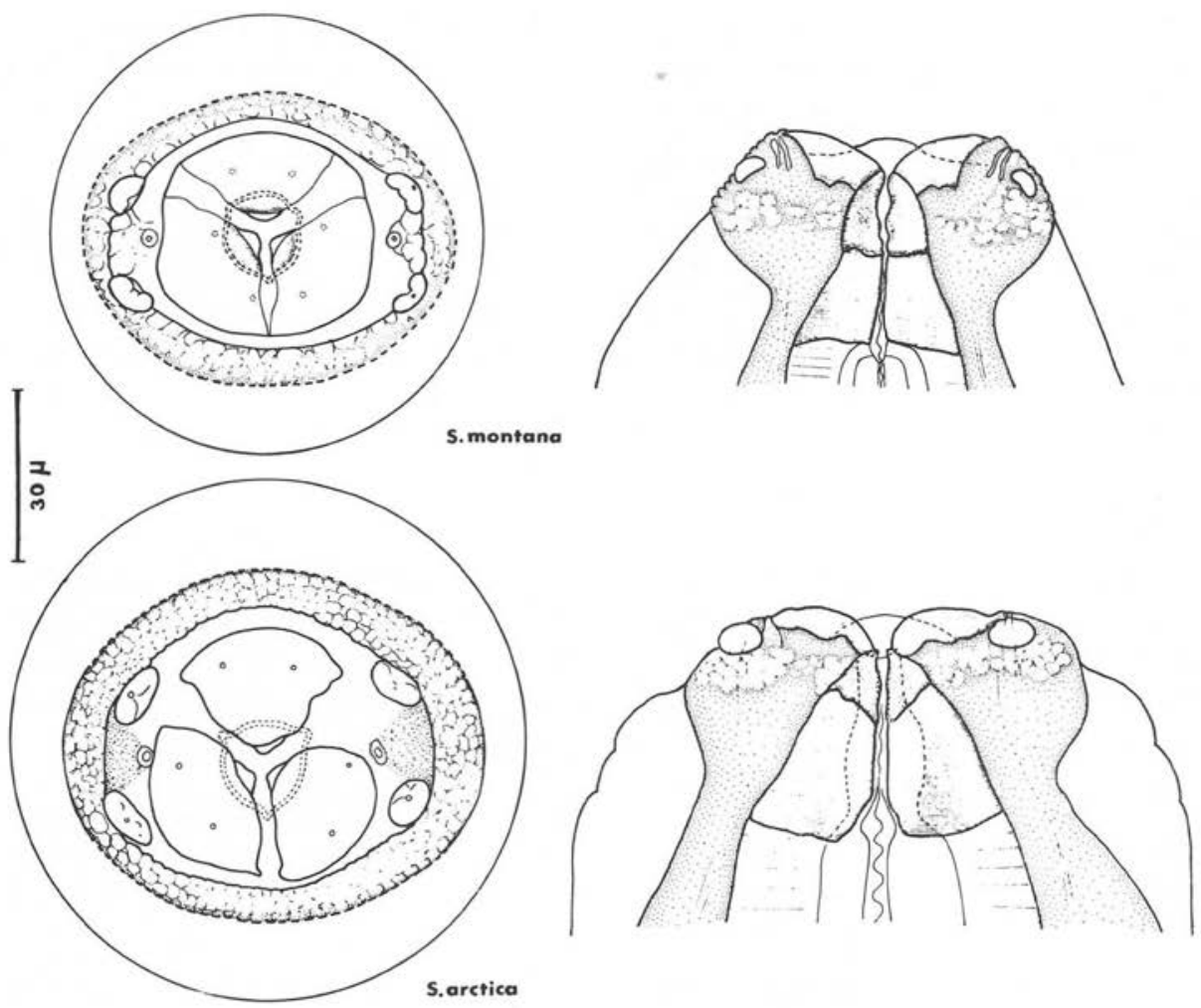

FIG. 11 


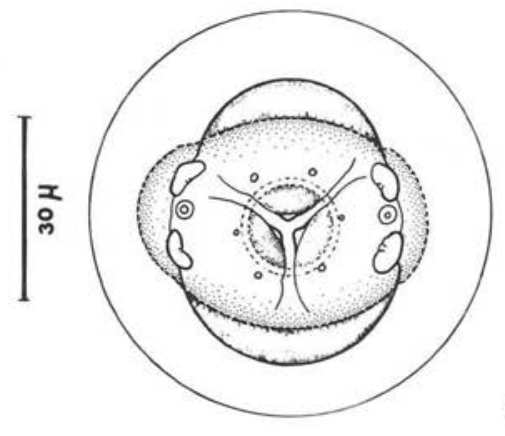

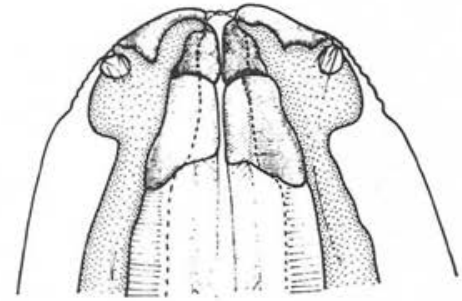

\section{S.venteli}

FIG. 12

Syphacia venteli Travassos, 1937 ; les types sont récoltés chez Nectomys squamipes au Brésil. Nous avons identifié à cette espèce des Syphacia parasites d'un autre Rongeur, Cricetidae de Colombie, Oryzomys caliginosus (Tomes), car leurs dimensions correspondent aux données de Travassos.

Chez $S$. venteli, le plateau céphalique est identique par sa taille et sa forme à celui de $S$. nigeriana ; l'écart des pores amphidiaux, en particulier, est le même chez les deux espèces, mais le masque facial est différent.

Les dimensions du spicule et du gubernaculum sont chez les mâles types 52-60 $\mu$ et $30 \mu$, et sur notre matériel $67 \mu$ et $27 \mu$. Le crochet accessoire n'est pas denté et mesure $13 \mu$ de long. L'appendice caudal est allongé. Les femelles portent deux ailes latérales qui naissent à $90 \mu$ de l'apex dans une vésicule haute de 95-100 $\mu$; elles mesurent de 10 à $11 \mu$ de large et disparaissent au niveau de l'anus. Les dimensions des œufs sont réduites : $78-80 \mu \times 32 \mu$ sur les femelles types, $82 \mu \times 33 \mu$ sur notre matériel.

\section{Groupe VI :}

Le plateau céphalique est aminci latéralement. Les papilles submédianes sont presque accolées aux amphides. La région péribuccale sans dessin des lèvres est dilatée et recouvre le plateau céphalique. Deux larges ailes cervicales s'impriment profondément dans la vésicule céphalique et remontent très près du rebord cépha!ique (fig. 13).

Un telle physionomie est observée chez cinq espèces et sous-espèces.

1. S. frederici Roman, 1945, parasite le gros intestin des Apodemus. Le spicule mesure 54-67 $\mu . \times 5 \mu$. Le gubernaculum, long de 24-30 $\mu$, est soudé à un crochet accessoire lisse sur sa surface externe. L'appendice caudal est court. Les œufs mesurent (d'après Roman, 1951) 88-124 $\mu \times 28-37,5 \mu$.

2. S. vandenbrueli Bernard, 1961, est récolté chez la Souris naine Micromys minutus Pallas en Belgique. La longueur du spicule donnée par Bernard, $1966 a$, 

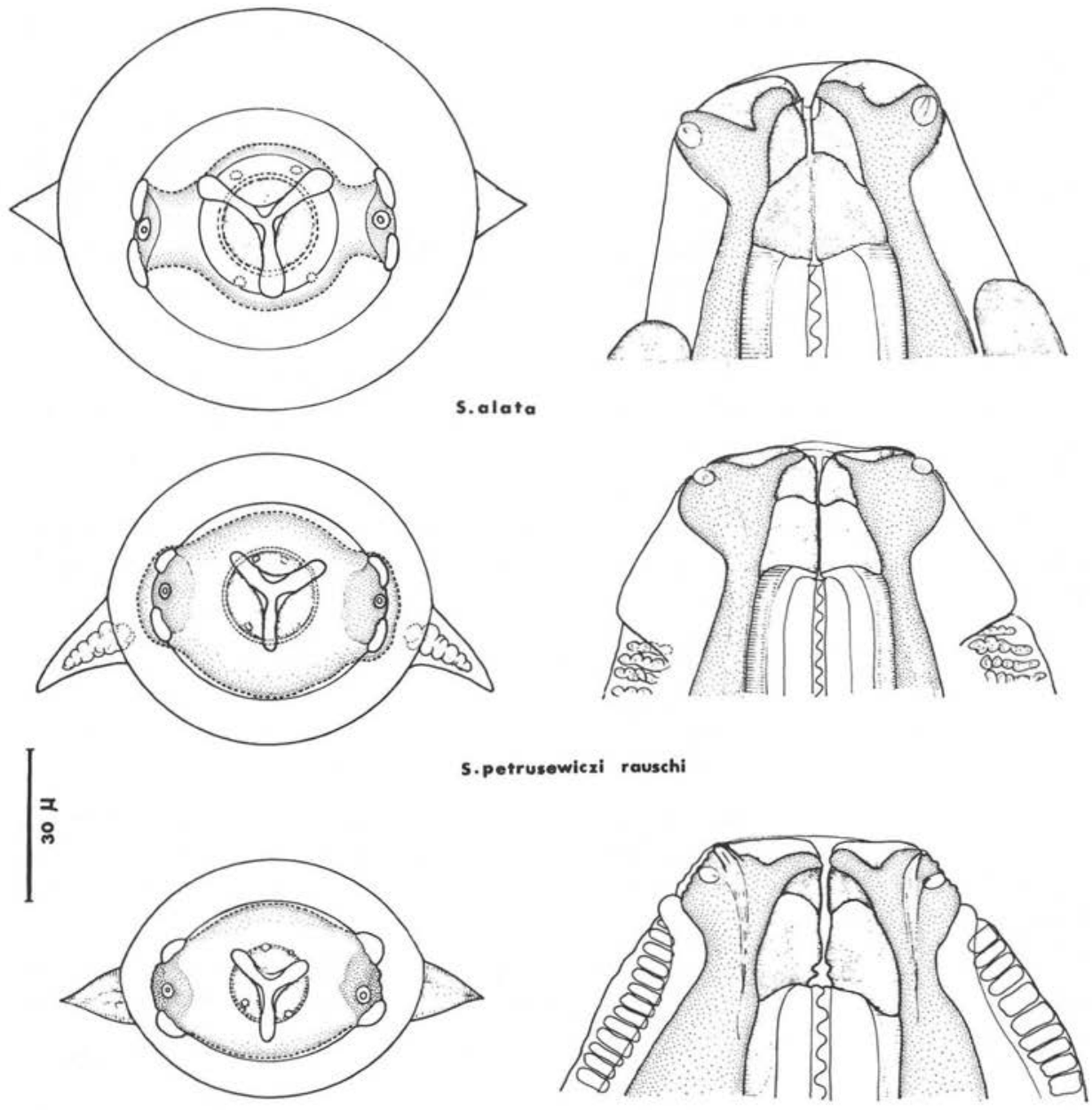

S.petrusewiczi
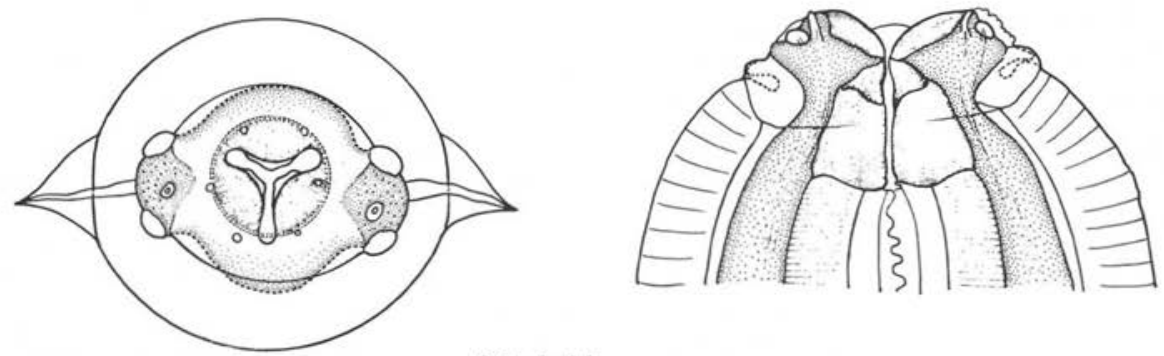

S.froderici

FIG. 13 
est de 40,5-56,7 $\mu$, et celle du gubernaculum 18,9-24,3 $\mu$. Les œufs mesurent $82-103 \mu$. $\times 26-41 \mu$.

3. S. petrusewiczi Bernard, 1966 b, parasite le caecum de Clethrionomys glareolus Schr. en Pologne. Le mâle reste inconnu. Les œufs mesurent 94,6-107 $\mu$ de long sur $34,4-40,85 \mu$.

4. La sous-espèce $S$. petrusewiczi rauschi Quentin, 1969, est récoltée chez Clethrionomys rutilus dawsoni (Merriam) à Anchorage, Alaska. Le mâle reste inconnu. Les cufs mesurent $100 \mu . \times 37 \mu$.

5. S. alata Quentin, 1968, est parasite de différents Cricetidae du Brésil et de Colombie: Zygodontomys lasiurus, Orizomys nigripes, Nectomys alfari. Le mâle présente trois mamelons cuticulaires ventraux. Les longueurs du spicule et du gubernaculum sont $76 \mu$ et $28 \mu$. Les œufs mesurent 95-97 $\mu \times 34-40 \mu$.

Chez ces cinq espèces et sous-espèces, les caractères cuticulaires des femelles sont remarquables, car les crêtes latérales et les ailes cervicales se modifient successivement d'une espèce à l'autre :

$S$. frederici. Les deux ailes latérales sont de largeur moyenne : $14 \mu$ dans la région cervicale, $9 \mu$ du niveau de l'œsophage, $2 \mu$ en arrière du pore excréteur. Elles sont cependant bien marquées, s'étendent jusqu'au masque facial et déterminent deux échancrures dans une très courte vésicule céphalique.

S. vandenbrueli. Les ailes latérales courent tout le long du corps du Nématode; elles s'élargissent dans le quart antérieur du corps où leur largeur atteint 20-25 $\mu$. Elles se prolongent fortement vers l'avant et s'impriment dans le masque facial comme chez S. frederici (cf. Bernard, 1966).

$S$. petrusewiczi. Il n'existe plus d'ailes latérales, mais deux ailes cervicales qui débutent juste en arrière du plateau céphalique sans l'atteindre. Ces ailes sont ornées d'éléments verruqueux larges de $24 \mu$ à $34 \mu$ qui apparaissent comme une modification locale de l'ornementation cuticulaire générale du corps. Ces éléments deviennent de plus en plus étroits et de plus en plus espacés ; l'ensemble va en s'amenuisant et l'aile disparaît dans la cuticule approximativement au niveau du pore excréteur.

$S$. petrusewiczi rauschi. Les deux ailes cervicales, larges de 20-25 $\mu$, naissent plus en arrière du plateau céphalique ; elles sont également soutenues par des épaississements cuticulaires et percées au niveau de l'anneau nerveux par deux très fines deirides ; ces ailes disparaissent en avant du pore excréteur sans être prolongées par des ailes latérales. La disposition des éléments verruqueux reste ici régulière sur toute la surface de chaque aile.

S. alata. La vésicule céphalique s'est dilatée. Les ailes cervicales ne sont pas ornementées mais elles sont élargies et renforcées à leur base. Leur largeur atteint $45 \mu$; elles débutent à $60 \mu$ de l'apex ; les deirides ne sont pas visibles. Les ailes s'arrêtent en avant du pore excréteur comme celles de $S$. petrusewiczi rauschi. 

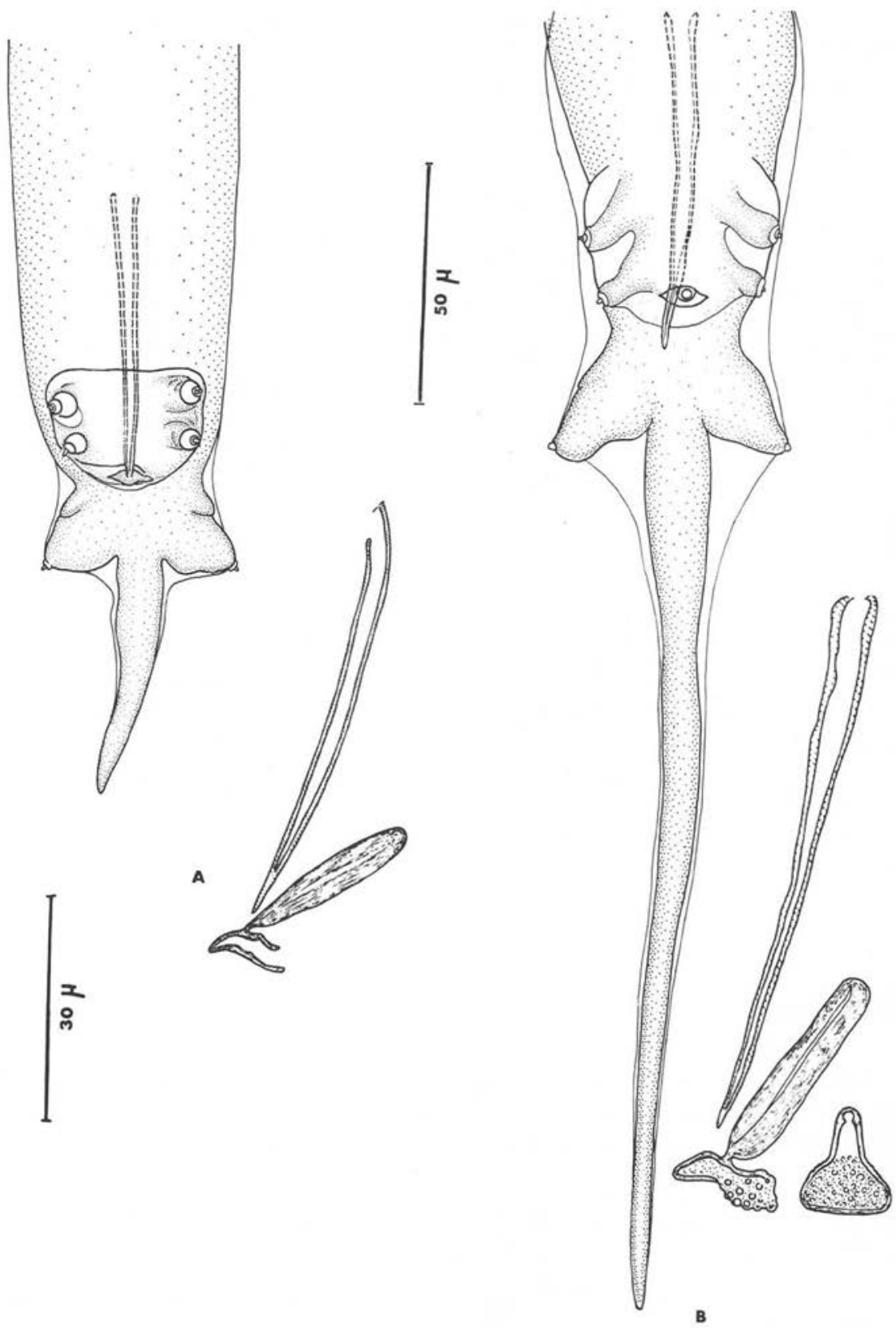

Fig. 14. - Bourses caudales et pièces génitales du mâle, A - S frederici, B - S. alata 
Les autres espèces de Syphacia sont profondément hétérogènes dans les dimensions et la forme de leur plateau céphalique, mais toutes sont caractérisées par des lèvres très épaisses.

Nous les avons classées en quatre groupes distincts :

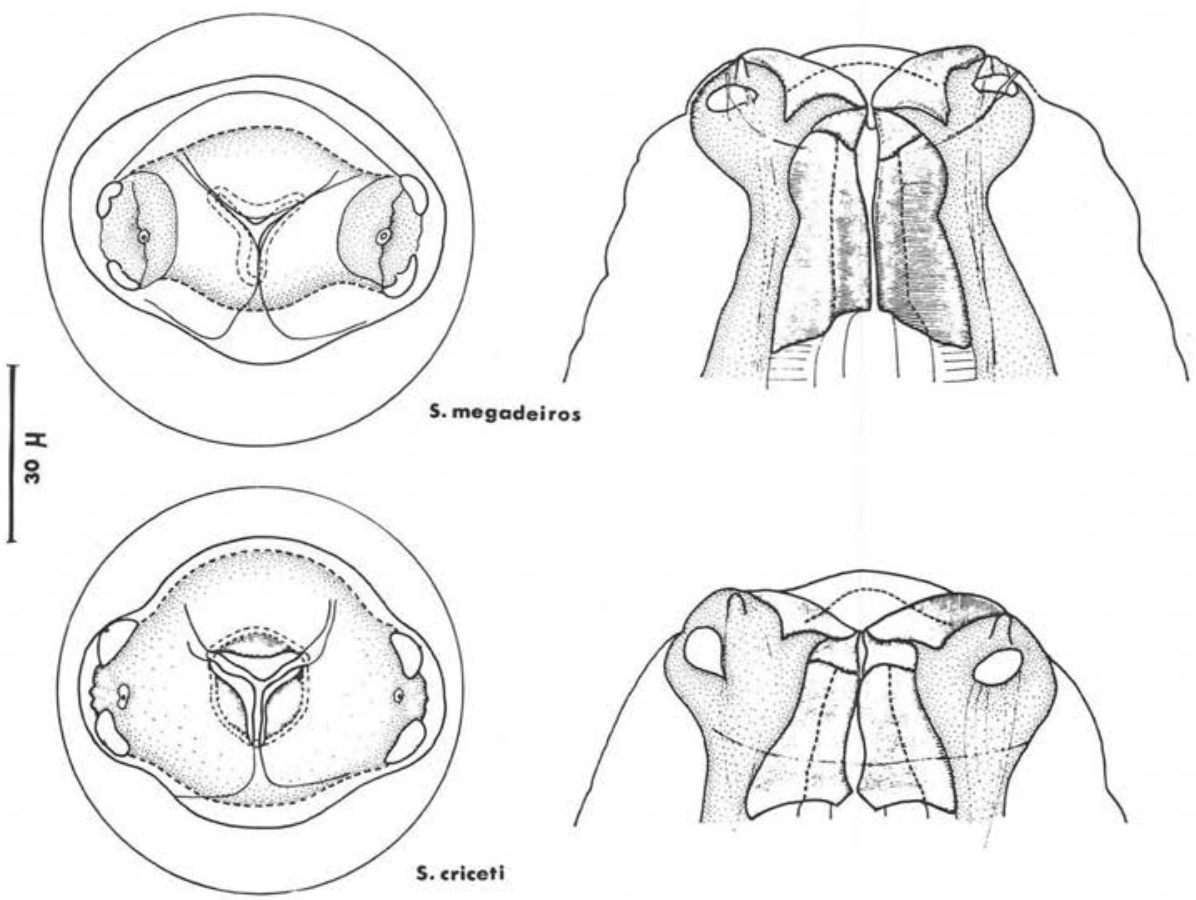

FIG. 15

\section{Groupe VII :}

Le plateau céphalique est étiré latéralement, l'écart des pores amphidiaux varie de $42 \mu$ à $50 \mu$. Les papilles submédianes sont rapprochées latéralement. Il n'existe pas d'ailes cervicales, mais deux deirides proéminentes au niveau de l'anneau nerveux (fig. 15).

Quatre espèces présentent cette physionomie et paraissent inféodées en Amérique aux Rongeurs Cricetidae de la sous-famille des Hesperomyinae.

S. peromysci Harkema, 1936, parasite, en Amérique du Nord, différentes espèces du genre Peromyscus. Tiner, 1948, donne une vue apicale de l'extrémité céphalique de cet Oxyure: le plateau céphalique est étiré latéralement, les papilles submédianes 
sont presque accolées aux amphides, l'écart des pores amphidiaux est approximativement de $42 \mu$.

Les dimensions du spicule et du gubernaculum sont, d'après Kruidenier, Mehra et Harkema, 1961, 58-70 $\mu$ et 26-37 $\mu$. Le crochet accessoire du gubernaculum est denté chez cette espèce et mesure 15-20 $\mu$ de long. La femelle ne présente pas d'ailes latérales. Les œufs mesurent 80-89 $\mu \times 23-31 \mu$.

S. samoridini Erickson, 1938, parasite des Rongeurs des genres Peromyscus et Reithrodontomys néarctiques. Cette espèce est très proche morphologiquement de $S$. peromysci. Elle en diffère principalement par la forme du vagin. Le spicule mesure 58-69 $\mu$, le gubernaculum 26-31 $\mu$. Ce dernier est soudé à un crochet denté long de $18 \mu$. Les dimensions des œufs sont 86-97 $\mu \times 25-27 \mu$.

S. criceti Quentin, 1969, parasite l'intestin grêle et le caecum des Cricetidae : Oryzomys subflavus (Wagner, 1842), Calomys callosus (Rengger, 1830) dans le Pernambuco Brésil, et le caecum de Kerodon sp. en Bolivie.

Le mâle est extrêmement contracté sur sa région ventrale, comme chez les espèces $S$. peromysci et $S$. samoridini, et présente aussi trois mamelons cuticulaires ventraux.

Le spicule mesure $96 \mu$. le gubernaculum $46 \mu$. Ce dernier est attaché à un crochet haut de $14 \mu$ dont la surface externe est ornée de seize bosses chitinoïdes. Celles-ci donnent au contour latéral une allure dentée (fig. 16). Il n'existe pas d'ailes latérales. Les œufs mesurent 83-87 $\mu \times 27-34 \mu$.

S. megadeiros Quentin, 1969. Seules les femelles sont connues chez cette espèce dans l'intestin grêle des Cricetidae: Rhipidomys latimanus et Oryzomys alfaroi en Colombie.

L'ouverture buccale est recouverte par la jonction des trois lèvres particulièrement développées.

En arrière de la vésicule céphalique, deux deirides proéminentes traversent latéralement la cuticule ; les deux crêtes latérales naissent en arrière des deirides et s'estompent dans la région anale. Elles résultent de l'épaississement sur les champs latéraux de fins replis cuticulaires qui ornent toute la surface du corps.

\section{Groupe VIII :}

Le plateau céphalique est très étiré latéralement. Le masque facial, dilaté, au contour arrondi, recouvre et englobe les papilles submédianes rejetées latéralement près des amphides (fig. 17). Cette physionomie caractérise deux Oxyures de Muridae de Centrafrique.

S. lophuromyos Quentin, 1966, est parasite de Lophuromys sikapusi Tem, République centrafricaine. Le mâle possède trois mamelons ventraux, un appendice caudal allongé. Les dimensions de ses pièces génitales sont : spicule, $75 \mu$, gubernaculum muni d'un crochet terminal non denté, $30 \mu$. La vésicule céphalique est bien développée. Les 


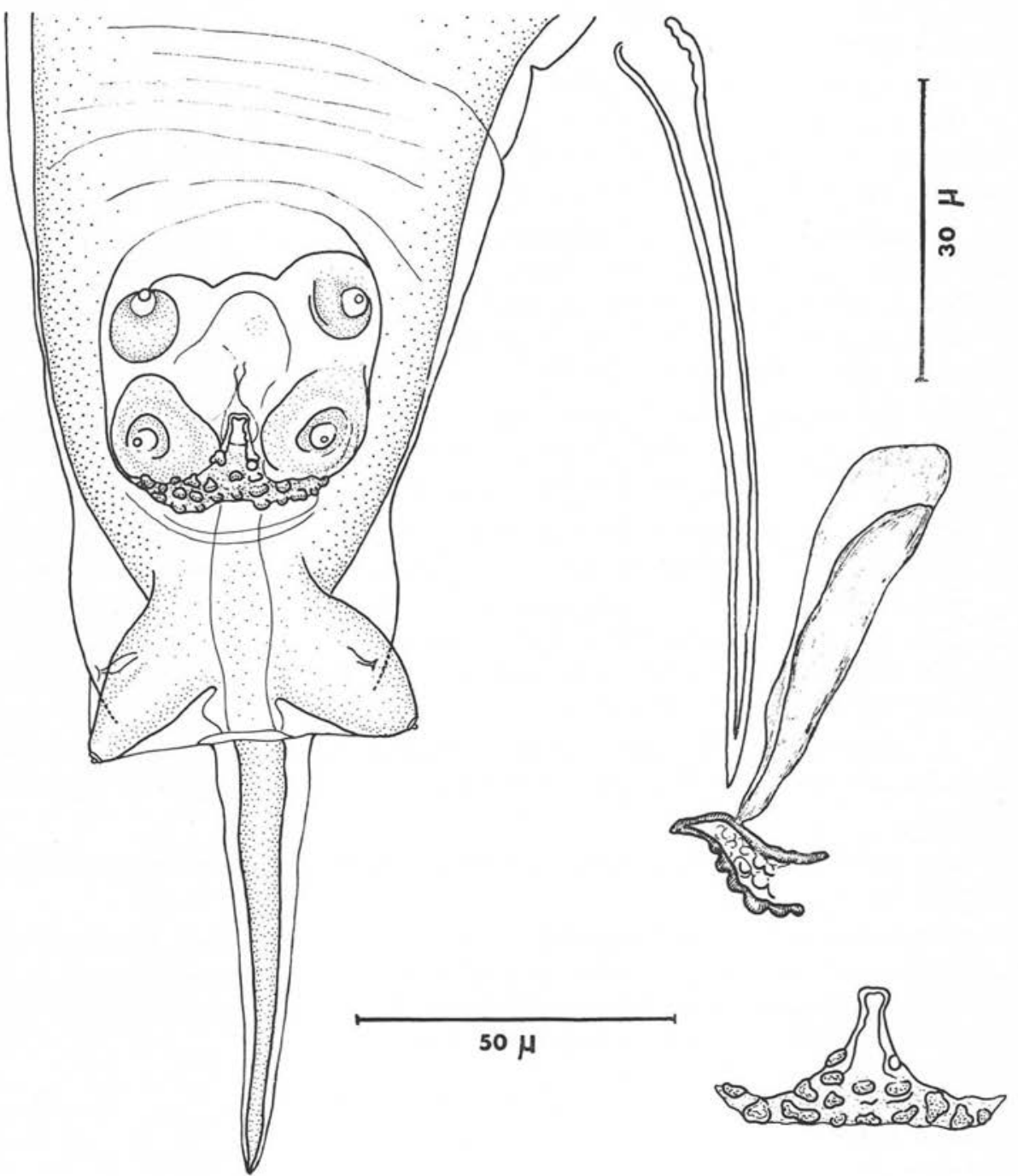

Fig. 16. - Bourse caudale et pièces génitales du mâlə de $S$. criceti

ailes latérales sont absentes. Les œufs mesurent $110 \mu \times 48 \mu$. La physionomie apicale de cet Oxyure rappelle celle de $S$. alata, parasite de Cricetidae d'Amérique du Sud. Il n'existe pas cependant d'ailes cervicales.

S. megaloon Quentin, 1966, parasite le caecum de Mus minutoides setulosus (Peters) du Congo-Léopoldville. 

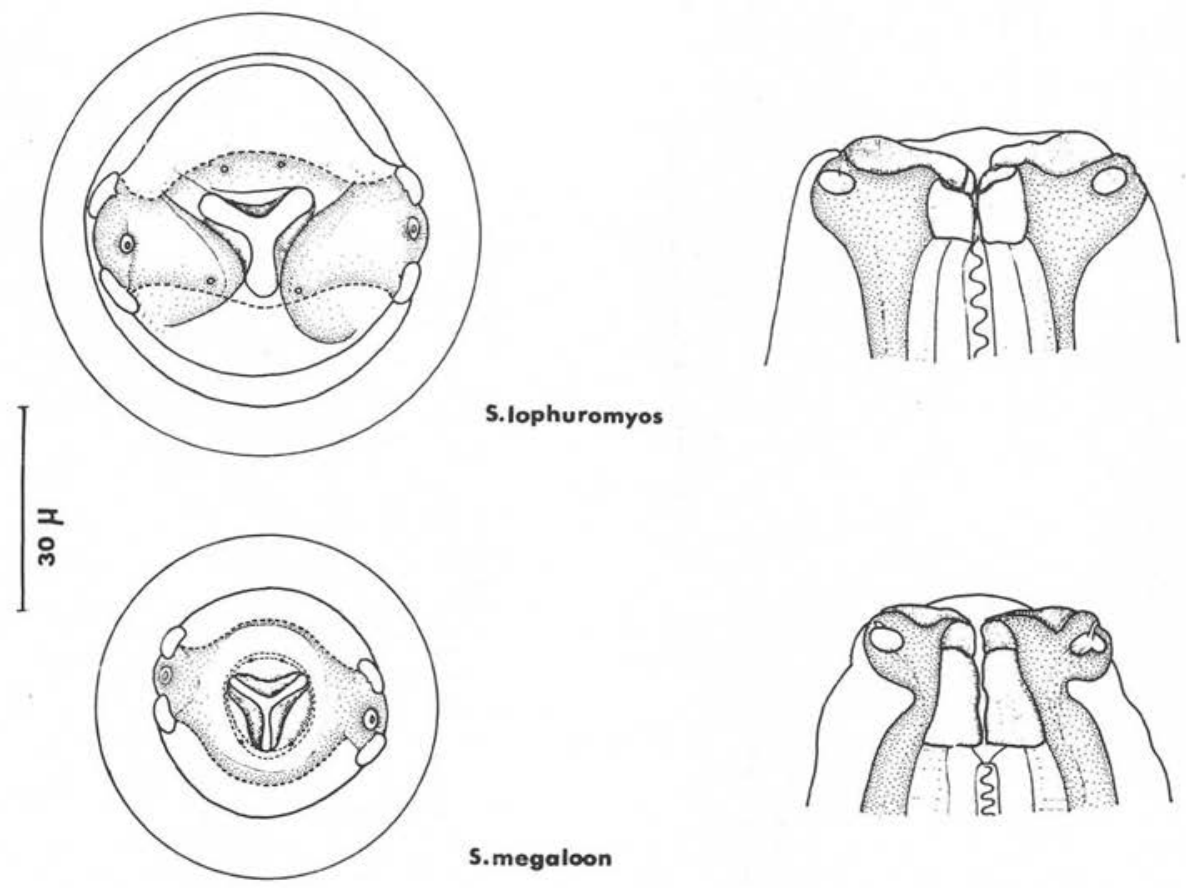

S. lophuromyos

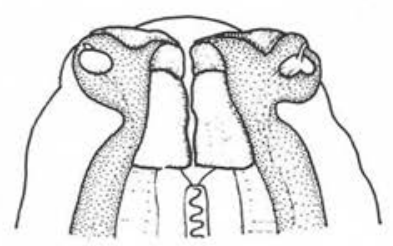

S.megaloon

FIG. 17

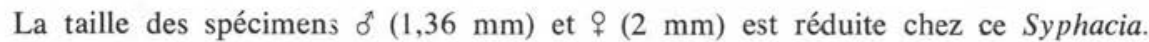

Le mâle présente trois mamelons ventraux, un spicule long de $61 \mu$ et un gubernaculum muni d'un crochet non denté long de $31 \mu$ (fig. 18).

Les ailes latérales sont absentes. Les dimensions des œufs, $150 \mu \times 60 \mu$, sont remarquables chez des femelles d'aussi petite taille.

\section{Groupe IX :}

Le plateau céphalique est ovalaire. Le masque facial est dilaté, les trois lèvres arrondies recouvrent totalement le plateau céphalique. Un cycle interne de quatre papilles est toujours visible (fig. 19).

Syphacia stroma (von Linstow, 1884).

Cette espèce parasite l'intestin grêle du Mulot Apodemus sylvaticus L. von Linstow, 1885, caractérise déjà cet Oxyure par la structure de la tête vue de face. Celle-ci 

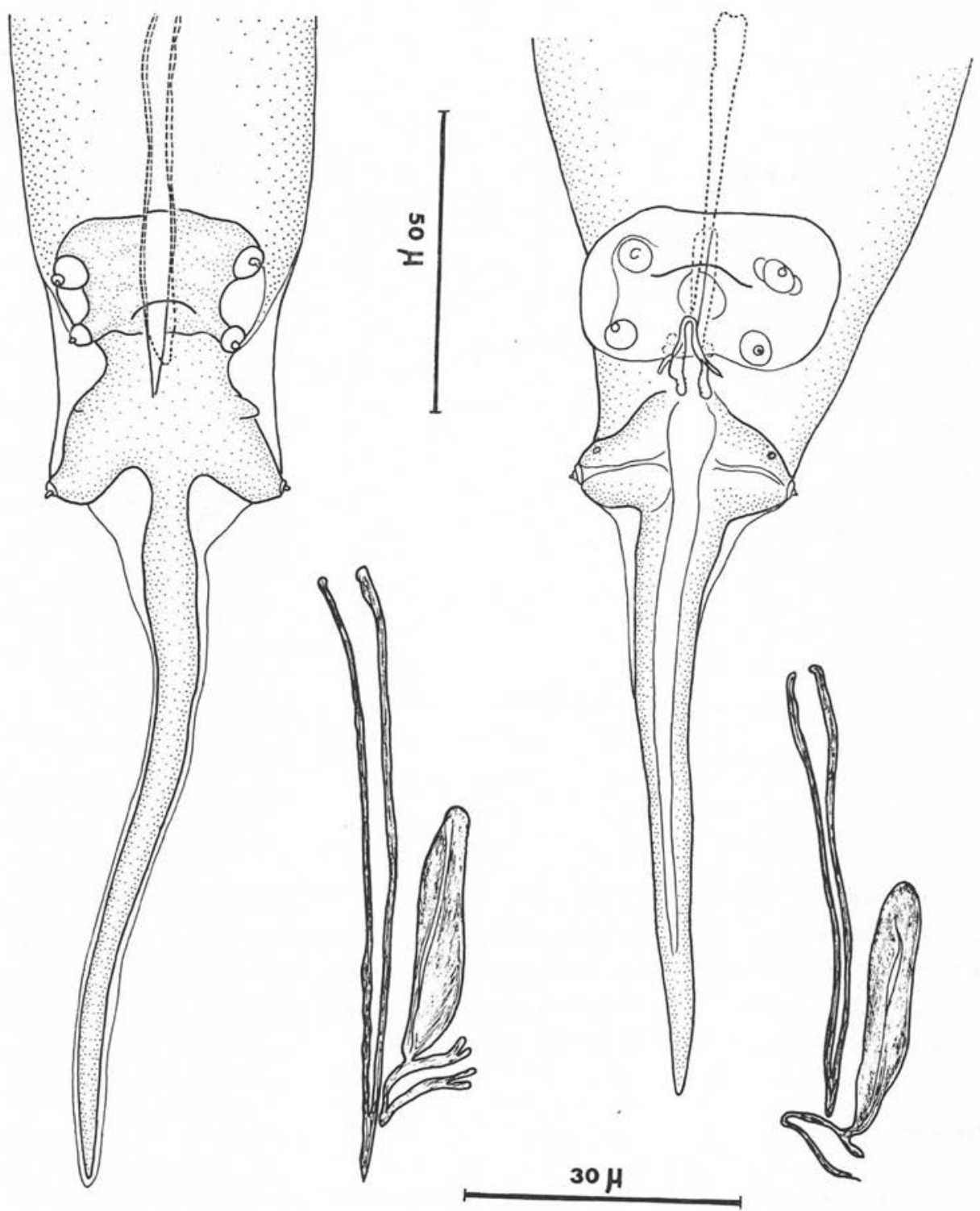

A

Fig. 18. - Bourses caudales et pièces génitales mâles de $S$. lophuromyos et de $S$. megaloon 
(fig. 19) a des pores amphidiaux écartés, et son masque facial recouvre latéralement le plateau céphalique. Morgan, 1932, montre la principale particularité de cet Oxyure en figurant la bourse caudale du mâle en vue ventrale. Il n'existe pas de constriction en arrière du cloaque, mais l'appendice caudal trapu est dans le prolongement du corps.

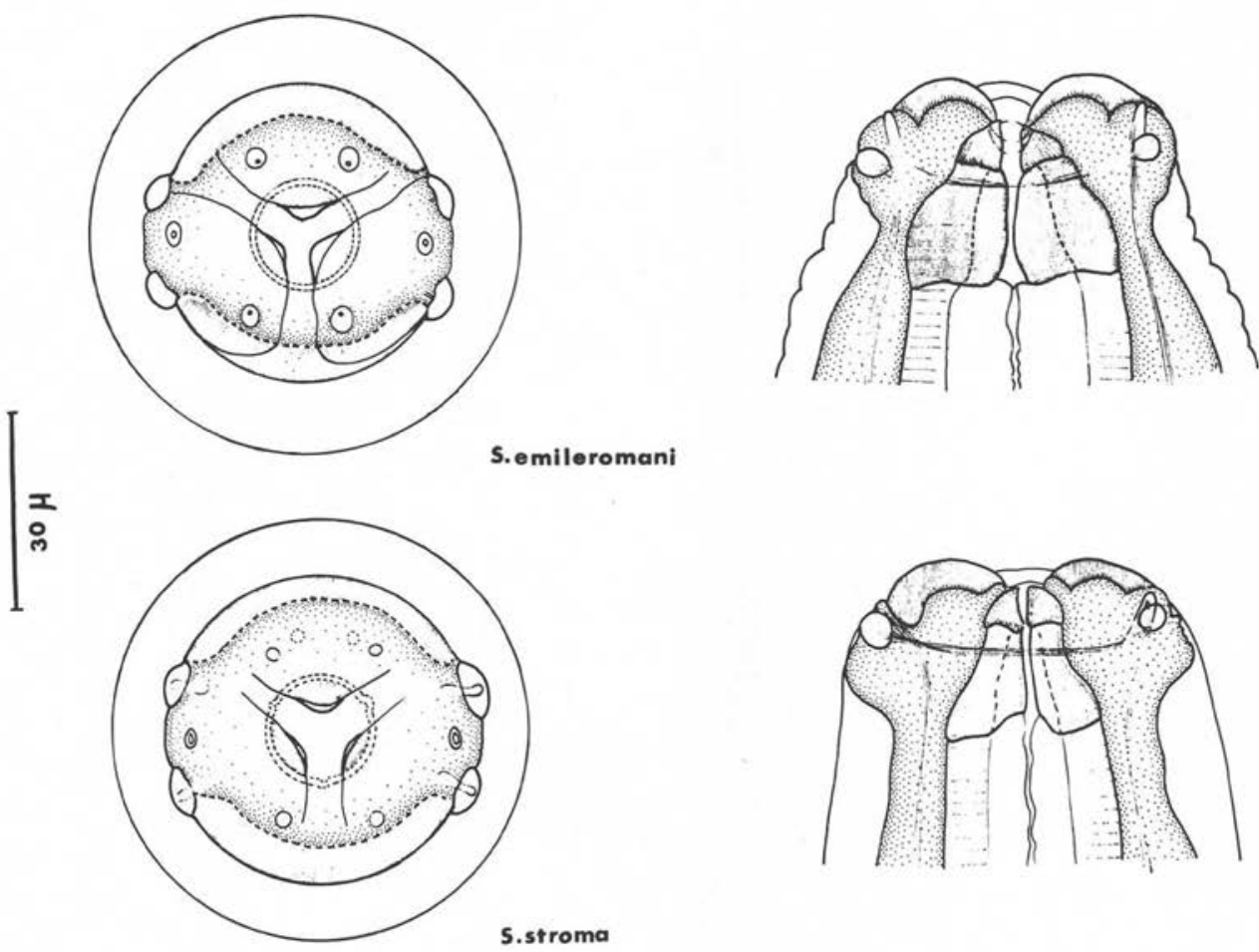

Fig. 19

Les longueurs du spicule et du gubernaculum sont, d'après Roman (1951), 75-90 $\mu$ et 25-47 $\mu$, d'après Bernard (1966a), 72-83 $\mu$ et 30-41 $\mu$. Le crochet accessoire du gubernaculum est recouvert de fins replis cuticulaires.

Bernard (1966 a) remarque que chez la femelle les crêtes latérales longitudinales sont peu marquées et naissent au niveau de la moitié antérieure de l'œsophage. Les œufs sont de grande taille, 123-150 $\mu \times$ 41-64 $\mu$ (d'après Roman, 1951).

S. emileromani Chabaud, Rausch et Desset, 1963.

Cette espèce est parasite d'Apodemus sylvaticus argenteus Tem., au Japon, Elle présente une extrémité apicale de forme et de dimensions identiques à celles de $S$. 


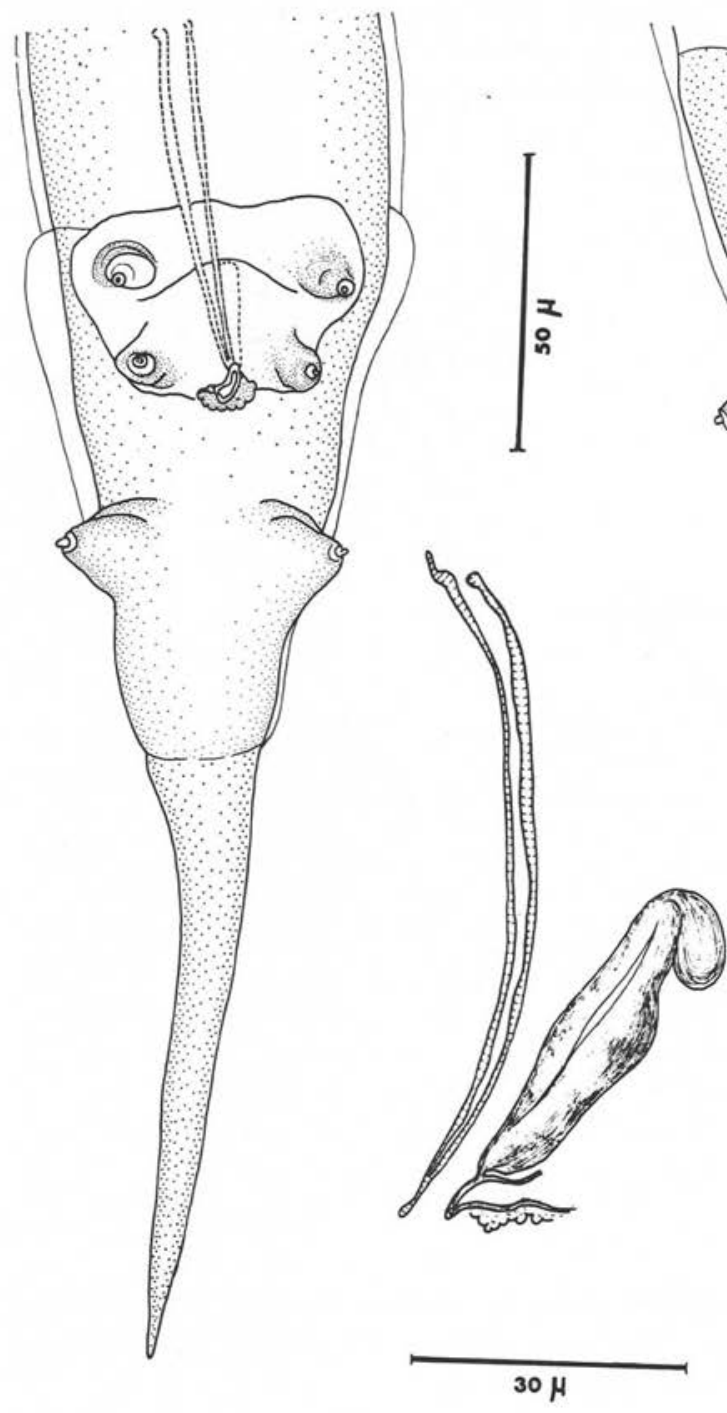

A

FIG. 20. - Bourses caudales et pièces génitales mâles, A - S. stroma, B - S. emileromani 
stroma. Le cycle interne, particulièrement distinct chez $S$. emileromani, est réduit à quatre papilles interno-médianes comme chez stroma. Les papilles céphaliques sont situées dans un sillon séparant le masque facial de la région cervicale. Ce sillon existe chez $S$. stroma, mais paraît moins prononcé.

- Les mâles ont un appendice caudal épais dans le prolongement du corps ; les dimensions et la morphologie des pièces génitales (4) correspondent à celles de $S$. stroma.

- Les ailes latérales chez la femelle sont faibles et naissent en arrière de la région céphalique.

L'espèce de $S$. emileromani est donc très proche de Syphacia stroma; seule la taille réduite des œufs chez $S$. emileromani, $85 \mu . \times 38 \mu$, permet de distinguer aisément les deux espèces.

\section{Groupe X :}

La physionomie apicale est caractérisée par le développement du masque facial tout entier dont le contour devient quadrangulaire, l'hypertrophie et l'asymétrie des papilles submédianes légèrement pédonculées, les dorsales étant plus éloignées des amphides que les ventrales (fig. 21).

Syphacia muris (Yamaguti, 1935) Yamaguti, 1941.

Les types ont été récoltés dans le gros intestin de Rattus norvegicus var. albus au Japon.

L'hôte, $R$. norvegicus, confère à cette espèce décrite au Japon une large répartition géographique. Hussey, 1956-1957, la signale aux U.S.A. et au Canada. Roman et coll., 1968, l'observent à Lyon chez des Rats de laboratoire.

Nous identifions à $S$. muris des $\delta$ et des $q$ parasites du caecum de Rattus norvegicus var. albus souche Lewis et Wistar, Paris.

Leur structure céphalique est définie ci-dessus.

Les mâles sont caractérisés par la longueur et la finesse de leur appendice caudal et les faibles dimensions des pièces génitales (fig. 22).

Les tailles du spicule et du gubernaculum soudé à son crochet sont respectivement de $56 \mu$ et $36 \mu$ (d'après Yamaguti, 1941), 42-54 $\mu$ et $28 \mu$ sur notre matériel. Roman et Pothier, 1968, relèvent pour longueur des spicules: 30-36 $\mu$.

Les femelles de cet Oxyure ne possèdent pas d'ailes latérales.

Les œufs ont une taille réduite : 72-82 $\mu \times$ 25-36 $\mu$ d'après Yamaguti, 1941, 64-76 $\times$ 23-32 $\mu$ d'après Roman et Pothier, 1968, 70-80 $\mu \times 28-40 \mu$ sur nos spécimens.

(4) La longueur du spicule de $195 \mu$ indiquée dans la description originale de $S$. emileromani est une erreur typographique. Sur un mâle paratype nous avons mesuré un spicule de $84 \mu$. Cette dimension correspond aux mensurations $75-90 \mu$ et $72-83 \mu$ données par Roman, 1951 et Bernard, 1966, pour le spicule de S. stroma. 


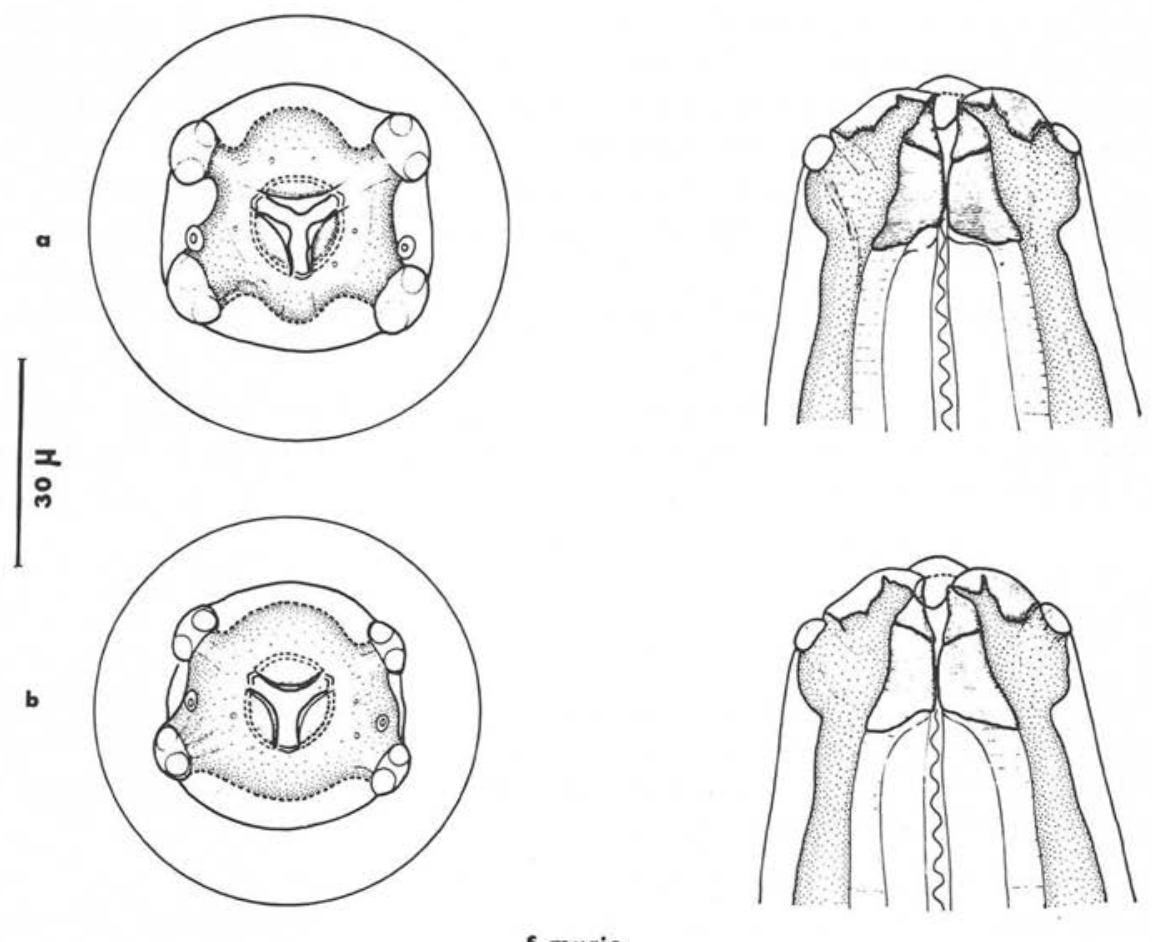

S. muris

FIG. 21. - Vues apicales de S. muris, a - $q$ de Syphacia parasites de Rattus norvegicus, b $\uparrow$ parasite de $R$. rattus

- Synonymie de S. baylisi Maplestone et Badhuri, 1942, avec S. muris (Yamaguti, 1935).

Roman, 1951, récolte chez Rattus rattus de la région lyonnaise des Syphacia qu'il identifie à Syphacia baylisi Maplestone et Badhuri, 1942, récolté chez le même hôte aux Indes, car les dimensions des femelles, et plus particulièrement celles des œufs, 63-79,5 $\mu \times 25-34 \mu$, correspondent à celles des types de $S$. baylisi. Il place en synonymie $S$. ratti Roman, 1945, avec $S$. baylisi. Bernard, 1961, $1963 a, 1966 a$, identifie des Oxyurides du Rat noir à $S$. baylisi. Il les retrouve aussi $(1961,1966)$ chez Rattus norvegicus, mais en nombre restreint.

Bernard caractérise cet Oxyure par la longueur et la finesse de l'appendice caudal du mâle qu'il récolte chez le Rat noir $(1966 a)$ et par l'absence de crêtes cuticulaires longitudinales chez les femelles.

Les dimensions des pièces génitales données par Bernard (1966) sont les suivantes : spicule 54 à $56,7 \%$, gubernaculum 27 à $35,1 \mu$. Elles sont semblables à celles de S. muris. 

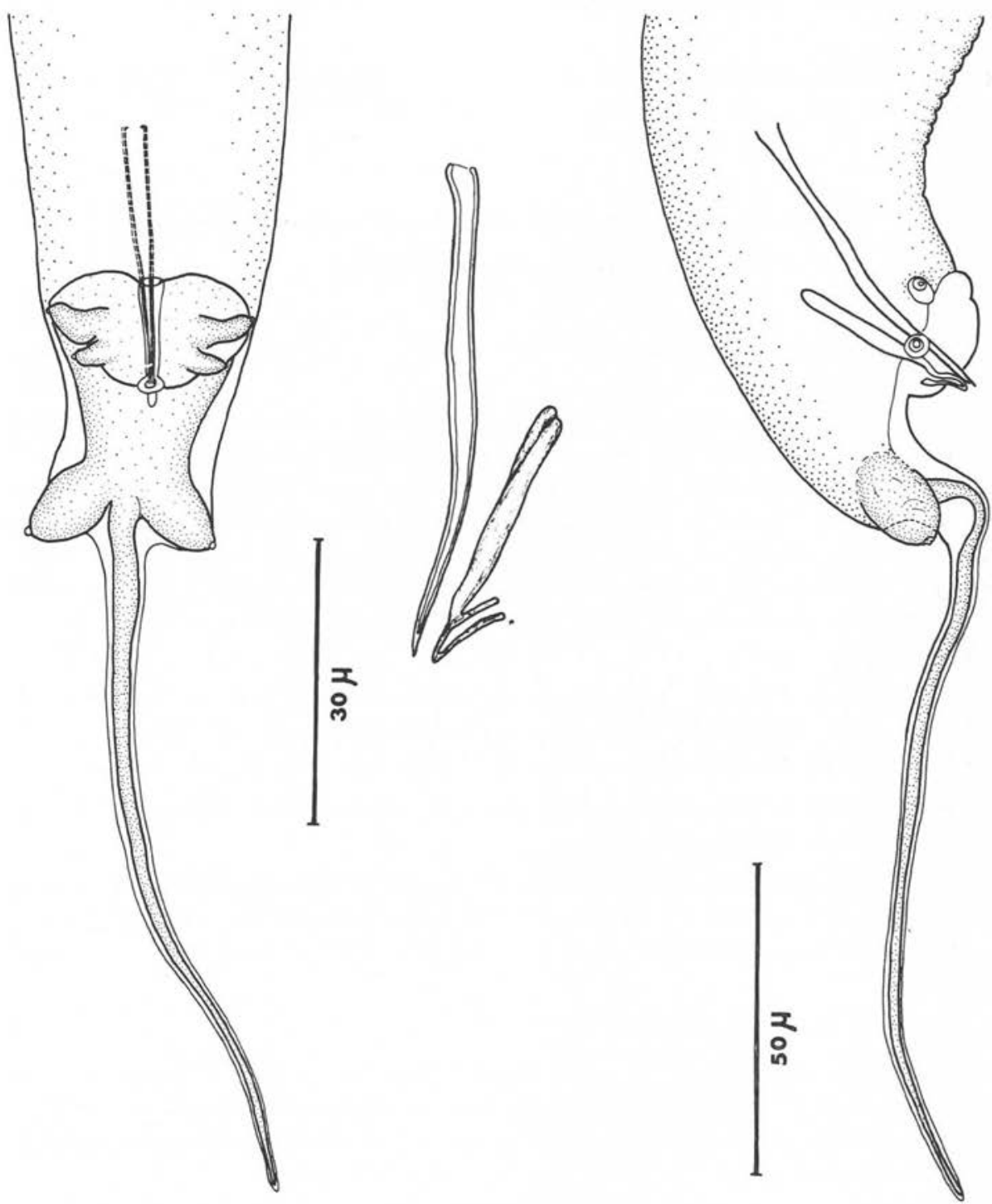

Fig. 22. - Bourse caudale en vue ventrale et latérale et pièces génitales du mâle de $S$. muris

Les dimensions que nous avons relevées sur les spécimens $q$ de $S$. muris correspondent aux données de Roman, 1951, et de Bernard, 1966, concernant S. baylisi. Grâce à l'obligeance du Professeur Roman, nous avons pu étudier les structures céphaliques d'un spécimen femelle de $S$. baylisi dét. Roman, parasite du caecum d'un Rattus Annales de Parasitologie humaine et comparée (Paris), t. 46, $\mathrm{n}^{\circ} 1$ 
rattus Saint-Didier-au-Mont-d'Or (Rhône); elles sont identiques à celles de $S$. muris (fig. 21).

C'est pourquoi nous proposons la synonymie, d'ailleurs suggérée par Tiner, 1948, de S. baylisi Maplestone et Badhuri, 1942, avec S. muris (Yamaguti, 1935).

\section{Espèces dont les structures céphaliques restent inconnues ou insuffisamment décrites}

\section{Sous-genre Syphatineria:}

- Région orientale: S. sciuri Mirza et Singh, 1934, est parasite de Sciurus palmarum. Le mâle ne porte que deux mamelons cuticulaires ventraux ; la dilatation cuticulaire dorsale figurée dans le dessin du mâle est due vraisemblablement à un artefact de fixation et ne doit pas être prise en considération dans la classification subgénérique de cet Oxyure. Celui-ci ne possède que deux mamelons cuticulaires ventraux et appartient par conséquent au sous-genre Syphatineria. Le spicule mesure $70 \mu$. Les auteurs ne mentionnent pas de crochet sur le gubernaculum. Les dimensions des œufs sont de $110 \mu \times 40 \mu$.

S. funambuli Johnston, 1965, est parasite de Funambulus pennanti Wroughton au Rajasthan. Cette espèce a été étudiée vraisemblablement d'après des spécimens immatures, car la taille des œufs $(22 \mu \times 21 \mu)$ est inhabituelle dans le genre Syphacia.

Le spicule et le gubernaculum sont faiblement chitinisés et mesurent $62 \mu$ et $11 \mu$. Il n'existe pas de crochet accessoire.

S. oceanica Schmidt et Kuntz, 1968, est parasite de Sundasciurus steerii juvencus aux Philippines. Le spicule est plus long, 70-73 $\mu$. Le gubernaculum, long de 44-49 $\mu$, a un crochet accessoire long de 11 ... Ce dernier est orné de deux dents sur sa face externe.

Les œufs mesurent 73-83 $\mu \times 23-29 \mu$.

- Région éthiopienne: S. pearsi Baylis, 1928, est parasite d'Heliosciurus isabellinus du Nigeria. Les dimensions du spicule et du gubernaculum sont $130 \mu$. et $70 \mu$. Le gubernaculum ne présente apparemment pas de crochet à son extrémité. Les œufs mesurent $100 \mu \times 37 \mu$.

S. paraxeri Sandground, 1933, est parasite de Paraxerus palliatus en Rhodésie. Les dimensions du spicule et du gubernaculum sont : 72-76 $\mu$ et 47-50 $\mu$. Le gubernaculum ne présente pas de crochet accessoire, la longueur de la queue du mâle est petite, et les œufs sont de taille réduite : 81-87 $\mu \times 29-32 \mu$.

- Région paléarctique: S. tjanschani Ablassov, 1962, = Syphacia sp. Ablassov, 1956, est parasite de Sciurus vulgaris exalbidus République de Kirghizie. Cet Oxyure est 
caractérisé par le développement des lèvres qui partagent le masque facial en trois secteurs d'égale importance et par deux larges ailes cervicales. Le spicule est chez cette espèce particulièrement allongé, 196-200 $\mu$, et le gubernaculum, long de $48 \mu$, est soudé à un crochet denté. Les œufs mesurent 87-90 $\mu \times 29-31 \mu$.

S. toschevi Petrov et Bayanov, 1962, est parasite de Sciurus vulgaris dans la même région géographique que $S$. tjanschani.

Cette espèce présente également deux larges ailes cervicales, un gubernaculum soudé à un crochet denté. Les dimensions du spicule sont toutefois plus réduites : 130-170 $\mu$, celles du gubernaculum sont par contre plus importantes : 100-110 $\mu$. L'appendice caudal est effilé chez le mâle. Les dimensions des œufs sont : 128-132 $\mu$ $\times 36-37 \mu$.

\section{Sous-genre Syphacia :}

Les espèces S. lahorea Akthar, 1955, parasite d'un Rongeur Sciurinae Pakistan et S. coli Schmidt et Kuntz, 1968, S. critesi Schmidt et Kuntz, 1968, S. magnispicula Schmidt et Kuntz, 1968, parasites de Sciurinae et de Petauristinae des Philippines, ont été citées précédemment dans la discussion de $S$. adami n. sp.

S. tinera Khera, 1954, est parasite d'un Rattus norvegicus Inde.

L'appendice caudal court du mâle distingue cette espèce de Syphacia muris, parasite du Rattus norvegicus, où l'extrémité caudale est très effilée.

Le diamètre de l'extrémité céphalique en vue latérale est de $46,5 \mu$.

Le spicule mesure $73 \mu$ de long, le gubernaculum $32 \mu$. Ce Syphacia ne présente pas d'ailes latérales. Les dimensions des œufs sont de 93-103 $\mu \times 34,9-46,5 \mu$.

\section{Sous-genre Syphabulea:}

L'espèce S. sobolevi Gubanov, 1964, parasite d'un « écureuil », n'est connue que par les mâles. Le spicule mesure 176-180 $\mu$, et le gubernaculum, particulièrement important, long de 90 à $95 \mu$, est soudé à un crochet denté.

\section{Interprétation des formes}

A) Evolution de l'extrémité céphalique entre les genres Lemuricola, Passalurus et Syphacia.

Les caractères céphaliques les plus primitifs du genre Syphacia paraissent dériver de structures connues chez les Cosmocercoidea. 
Dans la tribu des Oxyurinae, nous trouvons, en effet, à l'origine les Oxyures du genre Lemuricola Chabaud et Petter, 1959, parasites de Lémuriens. La tête présente une lèvre dorsale portant deux papilles submédianes et deux lèvres latéro-ventrales ornées chacune d'une papille submédiane et d'une amphide. Ces formations et cet appareil sensoriel rappellent étroitement la tête des Cosmocercides.

Chez les espèces du genre Passalurus Dujardin, 1845, parasites de Rongeurs Léporidés, l'extrémité apicale n'est plus divisée par trois lèvres. L'ouverture buccale est hexagonale ou triangulaire. L'appareil sensoriel est constitué par quatre papilles submédianes équidistantes les unes des autres. Les amphides sont latérales.

Dans le genre Syphacia, les formes primitives conservent cette tête circulaire et une ouverture buccale béante. L'apex porte quatre papilles submédianes équidistantes qui viennent au même niveau que les amphides.

L'évolution se fait :

a) par un allongement céphalique latéral,

b) par une migration de l'appareil sensoriel, les papilles céphaliques s'écartent de la bouche et deviennent de plus en plus latérales (5),

c) par une augmentation de la surface céphalique : le masque facial dilaté déborde dorsalement et ventralement le contour du plateau céphalique chez les formes les plus évoluées. Les lèvres ainsi constituées sont des néoformations, car elles ne portent plus de papilles céphaliques et n'ont par conséquent plus aucun rapport avec celles des Oxyures du genre Lemuricola.

\section{B) Répartition des espèces en fonction de leurs hôtes.}

\section{Syphacia parasites de Sciuridae.}

a) Evolution des caractères céphaliques.

Les caractères les plus primitifs: plateau céphalique circulaire, papilles céphaliques écartées les unes des autres, masque facial peu développé, sont rencontrés dans les espèces du premier groupe : $S$. eutamii, $S$. citelli, $S$. pallaryi, parasites de Rongeurs Sciuridae néarctiques et paléarctiques. Les documents paléontologiques situent l'origine des Sciuridae à l'Oligocène.

Dans le second groupe, l'espèce $S$. transafricana, parasite de Xerus de Dakar et de Somalie, marque, si l'on se réfère à l'hypothèse précédente, une étape dans l'évolution des structures apicales. Le plateau céphalique est très légèrement ovalaire; les papilles ont migré latéralement, ventralement aux commissures de la lèvre dorsale.

(5) Un phénomène comparable a été observé par Chabaud. 1952 et Anderson, 1967, dans l'évolution de l'extrémité céphalique d'un autre groupe de Nématodes: les Filaires. 
On sait que les Ecureuils du genre Xerus ont vécu en Europe au Miocène.

Enfin, dans le troisième groupe, les structures les plus différenciées, remarquables par le rapprochement latéral des papilles et par le développement cuticulaire du masque facial, se rencontrent à la fois chez des Syphacia parasites de Sciurinae et des Petauristinae d'Amérique du Nord et d'Eurasie (S. thompsoni, S. tjanschani) et chez des Sciurinae de Centrafrique ( $S$. adami).

b) Corrélations entre cette évolution céphalique et celle des caractères sexuels du mâle.

- Les Syphacia du premier groupe et du second groupe appartiennent tous au sous-genre Syphatineria Chabaud et Biocca, 1955. Les mâles portent deux mamelons cuticulaires ventraux.

Dans ce sous-genre, les pièces cuticulaires génitales du mâle sont simples, et le gubernaculum ne possède pas de crochet accessoire chez les espèces $S$. funambuli (Inde), S. paraxeri (Afrique), S. pearsi (Afrique) et $S$. sciuri (Inde). Le gubernaculum est muni d'un crochet chez $S$. citelli et chez $S$. eutamii (Amérique du Nord), $S$. pallaryi (Maroc), S. transafricana (Dakar, Ethiopie) et $S$. oceanica (Philippines). Chez ces deux dernières espèces, le crochet du gubernaculum est garni d'une à deux dents antérieures. Toutes ces espèces ont un spicule dont la longueur est inférieure ou égale à $100 \mu$. L'appendice caudal est court.

Deux espèces parasites de Sciurinae paléarctiques, S. tjanschani et $S$. toschevi caractérisées par le développement des lèvres, qui partagent le masque facial en trois secteurs d'égale importance, ont également des pièces génitales de grande taille (spicule, $130-200 \mu$; gubernaculum, 48-110 $\mu$ ) et un crochet accessoire orné de six dents environ.

- Dans le sous-genre Syphacia, trois mamelons ornent la face ventrale du mâle

Le spicule et le gubernaculum s'allongent et mesurent respectivement :

- $84 \mu$ et $54 \mu$ chez $S$. adami (Afrique).

- 100-112 $\mu$ et 57-65 $\mu$ chez $S$. coli (Philippines).

- $126 \mu$ et $63 \mu$ chez $S$. lahorea (Pakistan).

- 175-195 $\mu$ et 70-75 $\mu$ chez S. critesi (Philippines).

- 156-190 $\mu$ et 95 à $110 \mu$ chez $S$. thompsoni d'après Price, 1928.

- 210-240 $\mu$ et 100-130 $\mu$ d'après Li (Eurasie).

- 312-338 $\mu$ et 88-96 $\mu$ chez S. magnispicula (Philippines).

Chez les espèces $S$. adami et $S$. lahorea, dont le spicule et le gubernaculum ont une taille moyenne, le crochet n'est pas denté; il le devient chez $S$. coli, S. critesi, 
S. thompsoni et $S$. magnispicula (6) avec une augmentation croissante du nombre de dents corrélative à l'allongement de ces pièces génitales.

- Dans le sous-genre Syphabulea, quatre mamelons cuticulaires ornent la surface ventrale des mâles de $S$. sobolevi Gubanov, 1964 (Russie). Ces mâles présentent par ailleurs d'autres caractères qui nous paraissent évolués : spicule long de 176 à $180 \mu$, gubernaculum épais long de 90 à $95 \mu$ soudé à un crochet denté.

\section{C) Intérêt phylétique.}

Le nombre de mamelons cuticulaires sur la face ventrale du mâle utilisé pour les divisions subgénériques ne coïncide pas avec un groupe zoologique particulier, puisque chez les Rongeurs Sciurinae cette ornementation varie de deux à quatre mamelons. L'augmentation de ces éléments cuticulaires nous paraît par contre résulter d'une évolution qui se manifeste à la fois avec la différenciation des structures céphaliques et celle des pièces génitales mâles.

L'évolution de cet ensemble de caractères est particulier aux espèces parasites de Sciuridae; celles-ci constituent une série évolutive continue, indépendante des autres Syphacia répartis chez les autres familles de Rongeurs.

2. Syphacia parasites de Cricetidae, Gerbillidae, Muridae et Microtidae.

Chez les Syphacia parasites des Rongeurs Cricetidae, Gerbillidae, Muridae et Microtidae, il n'existe plus d'évolution aussi marquée des caractères céphaliques et génitaux, mais une dispersion des formes à partir d'un type fondamental.

Toutes ces espèces, en effet, présentent d'emblée :

- un plateau céphalique ovalaire et des papilles submédianes rapprochées latéralement des amphides,

- trois mamelons cuticulaires ventraux chez le mâle,

— un spicule dont la tailie est toujours inférieure à $100 \mu$, et un gubernaculum relié à un crochet accessoire par une très mince attache.

La spéciation chez ces Oxyures aboutit, selon la conception d'A. J. Petter, 1966, à partir de formes ancestrales communes, par suite de l'éloignement phylétique ou géographique des hôtes, à l'individualisation de formes vicariantes présentant de grandes affinités morphologiques, mais différant par quelques caractères et qui se correspondent chez des hôtes de régions isolées les unes des autres.

Dans cet ensemble, les structures les plus primitives paraissent se réaliser chez l'espèce Syphacia mesocriceti, parasite de Cricetidae, où les lèvres sont inexistantes (groupe IV).

(6) Les quatre espèces $S$. coli, $S$. critesi, $S$. thompsoni et $S$. magnispicula sont toutes caractérisées par des œufs dont l'opercule très large occupe la face bombée de la coque. 
Trois groupes principaux (V, VI et VII) rassemblent la majorité des espèces. Dans chacun d'eux, la spéciation ne porte que sur des éléments morphologiques discrets, tels que l'allongement relatif du plateau céphalique marqué par l'écart des pores amphidiaux, le dessin des lèvres, la dilatation faciale, la présence ou l'absence d'ailes cervicales et latérales, l'aspect de l'appendice caudal et celui du crochet du gubernaculum.

\section{Groupe V:}

S. nigeriana, parasite de Microtidae holarctiques, de Gerbillidae et Muridae éthiopiens. Les formes holarctiques et éthiopiennes sont identiques. Nous pensons qu'elles sont contemporaines et que leur large distribution géographique coïncide avec l'extension des Microtidae dans toute la région holarctique à la fin du tertiaire et à l'invasion du continent africain par les Muridae à la même époque.

Quatre espèces en sont des formes vivariantes:

S. arctica (Alaska) et S. montana (Japon), parasites de Microtidae, diffèrent de $S$. nigeriana par un plateau céphalique de grande taille et ne se distinguent entre elles que par les dimensions des œufs.

S. obvelata, parasite de la Souris domestique, a également une extrémité céphalique élargie, mais le dessin des lèvres n'est pas marqué.

S. venteli est parasite de Cricetidae en Amérique du Sud. Sa physionomie rappelle celle de $S$. nigeriana, mais les lèvres sont dilatées. La présence de cet Oxyure en Amérique du Sud daterait des échanges continentaux qui se sont particulièrement intensifiés entre les deux Amériques au Pliopléistocène.

\section{Groupe VI :}

S. frederici parasite le caecum de l'Apodemus sylvaticus (Muridae). Sa répartition géographique, donnée par Bernard (1963a), couvre la région méditerranéenne: Afrique du Nord, Espagne, Italie, France de l'Est et du Sud-Est, et l'Europe occidentale : Belgique, Allemagne, Pologne.

S. vandenbrueli parasite le caecum de Micromys minutus (Muridae) en Belgique.

S. petrusewiczi parasite le caecum de Clethrionomys glareolus (Microtidae) (7) en Pologne. Cette espèce n'a en effet jamais été trouvée par Bernard (1966 b) sur les quelque 400 Campagnols roux qu'il a capturés en France, en Belgique et en Allemagne.

(7) Les Microtidae du genre Clethrionomys sont parasités par quatre espèces et sous-espèces différentes de Syphacia selon la région géographique. S. montana (Japon), S. nigeriana (France), $S$. petrusewiczi (Pologne) et $S$. petrusewiczi rauschi (Alaska). 
S. petrusewiczi rauschi parasite le caecum d'un Clethrionomys en Alaska.

$S$. alata parasite différentes espèces de Cricetidae de Colombie et du Brésil.

Toutes présentent un plateau céphalique étiré latéralement, deux ailes cervicales qui s'impriment plus ou moins profondément dans la vésicule céphalique.

La même forme se conserve donc chez des Syphacia parasites de Rongeurs de familles différentes, mais, au cours de cette dispersion géographique, de légères variations, disparition des ailes latérales, élargissement et ornementation des ailes cervicales ( $S$. petrusewiczi), dilatation du masque facial ( $S$. alata), individualisent chaque espèce. L'appendice caudal, court chez $S$. frederici, devient allongé chez $S$. alata.

\section{Groupe VII :}

Il est particulièrement homogène, car les quatre espèces qui la constituent: $S$. samoridini, $S$. peromysci, $S$. criceti et $S$. megadeiros, sont toutes parasites de Cricetidae néarctiques et néotropicaux de la sous-famille des Hespsromyinae, et présentent les mêmes caractères céphaliques et génitaux.

Les papilles submédianes sont très rapprochées latéralement. Les ailes cervicales sont absentes, mais deux deirides proéminentes percent la cuticule au niveau de l'anneau nerveux. Le crochet du gubernaculum est denté.

Ces éléments morphologiques caractérisent également certains Syphacia de Sciuridae holarctiques. Cependant, nous pensons qu'ils apparaissent parallèllement chez des rameaux indépendants et évolués, car les physionomies céphaliques diffèrent. Les Syphacia d'Hesperomyinae ne peuvent donc s'être isolés directement à partir de ces Syphacia de Sciuridae, déjà très différenciés morphologiquement.

\section{Groupe VIII :}

Les espèces éthiopiennes $S$. lophuromyos, parasite du caecum de Lophuromys sikapusi, et $S$. megaloon, parasite de Mus minutoides et Mus setulosus du Congo, présentent par convergence: absence d'ailes latérales, plateau céphalique très étiré latéralement et masque facial dilaté, la physionomie de certains Syphacia de Cricetidae néotropicaux. Ces deux espèces ont un appendice caudal très allongé chez le mâle.

\section{Groupe IX :}

S. stroma et son vicariant $S$. emileromani sont parasites de l'Apodemus sylvaticus.

Les caractères faciaux et surtout la morphologie très particulière de l'appendice zaudal chez le mâle isolent ces formes des autres espèces congénères. 
S. stroma n'occupe pas le caecum du Mulot (biotope de l'espèce $S$. frederici), mais l'intestin grêle.

S. muris: cette forme ne peut être également rattachée à aucune autre, car le plateau céphalique très réduit supporte des papilles submédianes pédonculées et un masque facial dilaté. taille.

L'appendice caudal est long et effilé, mais les pièces génitales sont de très petite

\section{Conclusion}

En conclusion, l'étude des structures apicales et génitales des espèces du genre Syphacia permet d'indiquer approximativement la position zoologique relative des espèces. Le plateau céphalique circulaire chez les formes les plus primitives devient fortement étiré dans le sens latéral chez celles qui paraissent les plus évoluées. Ce caractère évolue avec une migration latérale des papilles et une dilatation générale du masque facial.

Chez les Syphacia parasites de Sciuridae, l'évolution des caractères céphaliques s'accompagne d'une augmentation du nombre des mamelons cuticulaires (sous-genres Syphatineria, Syphacia et Syphabulea) et d'une différenciation des pièces génitales du mâle. Les formes qui en résultent constituent les étapes d'une série évolutive dont l'origine paléontologique, contemporaine de celle de ses hôtes fondamentaux, remonterait à l'Oligocène.

Dans les familles de Rongeurs (Cricetidae, Gerbillidae, Muridae et Microtidae), nous ne trouvons plus de formes primitives: toutes les espèces dont les mâles sont connus appartiennent au sous-genre Syphacia, et l'extrémité céphalique est étirée latéralement.

Chez ces Syphacia, il n'existe plus d'évolution parallèle des différents caractères, mais des spéciations consécutives d'une dispersion géographique des espèces à la fin de l'époque tertiaire.

$$
* *
$$

\section{Remerciements}

Nous exprimons notre vive gratitude au Professeur Bernard, de l'Ecole supérieure d'Agriculture de Tunis, qui nous a fait parvenir des Syphacia récoltés par ses soins en Europe et en Afrique du Nord, au Docteur Little, de l'Université de Tulane (U.S.A.), qui nous a confié les Syphacia parasites de Cricetidae de Colombie, au Docteur R. Rausch, de l'Artic Health Research, Anchorage, Alaska, grâce à qui nous avons pu 
étudier des Syphacia de la faune néarctique, au Professeur Roman, de la Faculté de Médecine de Lyon, qui nous a communiqué des Syphacia du Rat noir.

\section{Bibliographie}

Ablassov (N. A.), 1960. - Syphacia species Ablassov 1956. Osnovi Nema'odologi, VIII, 380-382, fig. 195-196.

—, 1962. - Nouvelle espèce de Nématode du genre Syphacia Seurat, 1916 de Sciurus vulgaris exalbidus, Izvestia. Acad. Sc. Kirgiz, S.S.R. Ser. Biol., 4 (4), 179-181, fig 1 et 2.

AKthar (S. A.), 1955. - Syphacia lahorea. sp. n. a new nematode parasitic in pennant's squirrel. Pakist. Jouın. sc. Res., 7 (1), 1-3.

ANDERSON (R. C.), 1967. - The comparative morphology of cephalic structures in the superfamily Filarioidea (Nematoda). Canad. Journ. Zool., 46, 181-199, fig. 1-81.

Baylis (H. A.), 1928. - On a collection of Nematodes from Nigerian Mammals (Chiefly Rodents). Parasit., 20 (3), 280-304, fig. 1-25.

Bernard (J.), 1961. - Liste des Nématodes parasites des Micromammifères de la faune belge. Ann. Par. Hum. Comp., 36 (5-6), 775-784.

—, 1963 (a). - Etude sur la faune parasitaire de Tunisie. I. Nématodes parasites des Muridae. Arch. Inst. Past. Tunis, 40, 5-64, 4 figs.

-, 1963 (b). - Notules Helminthologiques. V. Arch. Inst. Past. Tunis, 40, 65-74, tabl. 1-3.

—, 1964. - Nématodes de Micromammifères récoltés dans le Marais vendéen. Vie et Milieu, 15 (2), 451-456.

-, 1966 (a). - Les Syphacia spp. parasites des rongeurs de la faune belge: Syphacia vandenbrueli de Micromys minutus Pall. Bull. Rech. Agron. de Gembloux, 1 (3), 345-358, fig. 1, tabl. 1-5.

—, 1966 (b). - Nématodes de Micromammifères récoltés en Europe Centrale. Arch. Inst. Past. Tunis, 4, 609-632, fig. 1.

Chabaud (A.-G.), 1952. - Le genre Dipetalonema Diesing 1861. Essai de classification. Ann. Parasit. Hum. Comp., 27 (1-2-3), 250-285, fig. 1-8.

- et Brocca (E.), 1955. - Vicariances spécifiques (et non génériques) chez des Oxyures parasites de Xerus africanus. Description de Syphacia transafricana n. sp., division du genre Syphacia Seurat 1916. Bull. Soc. Zool. France, 80 (2-3), 124-131, fig. 1-4.

—, Brygoo (E.-R.) et Petter (A.-J.), 1965. - Les Nématodes parasites de Lémuriens malgaches. VI. Description de six espèces nouvelles et conclusions générales. Ann. Parasit. Hum. Comp., 40 (2), 181-214, fig. 1-7.

— et Petter (A.-J.), 1959. - Les Nématodes parasites de Lémuriens malgaches. II. Un nouvel Oxyure: Lemuricola contagiosus. Mém. Inst. Sc. Madag., 13, sér. A, 27-132, fig. 1-2.

—, Rausch (R.-L.) et Desset (M.-C.), 1963. - Nématodes parasites de Rongeurs et Insectivores japonais. Bull. Soc. Zool. France, 88 (5-6), 489-512, fig. 1-9. 
Erickson (A. B.), 1938. - Parasites of some Minnesota Cricetidae and Zapodidae and host catalogue of Helminth parasites of native American mice. Ann. Midl. Nat., 20, 575-589.

Gubanov (N. M.), 1964. - Helminthofaune des Mammifères d'importance économique dans le yakut A.S.S.R. Izdaltesvo «Nauka», 1-164, fig. 1-48, tabl. 1-61.

Harkema (R.), 1936. - The parasites of some North Carolina rodents. Ecol. Monogr., 6, 151-232, fig. 1-5.

Hussey (K. L.), 1956. - Syphacia muris and its distribution. J. Parasit., 42 (4 sect. 2), 13-14.

—, 1957. - Syphacia muris vs S. obvelata in laboratory rat and mice. J. Parasit., 43 (5), 555-559, fig. 1-11.

Johnston (S.), 1965. - A new Nematode of the genus Syphacia (Oxyuroidea) from the squirrel, Funambulus pennanti from Rajasthan, India. Proc. Zool. Soc. Calcutta, 20, 83-85, fig. 1-2.

KHERA (S.), 1954. - Nématodes parasites of some Indian Vertebrates. Ind. Journ. Zool., 6 (2), 27-133, fig. 1-100.

Kruidenier (F. J.), Mehra (K.) et Harkema (R.), 1961. - Comparative studies of Syphacia peromysci and S. samoridini (Nematoda, Oxyurida). J. Parasit., 47 (1), 47-51, fig. 1-5.

LI (H. C.), 1933. - Report on a collection of parasitic Nematodes, mainly from North China Part III. Oxyuroidea. Chin. Med. Journ., 47, 1307-1325.

Linstow (O. von), 1884. - Helminthologisches. Arch. Naturgesch., 50 (1), 125-145.

-, 1885. - Beobachtungen an bekannten und neuen Nematoden und Trematoden. Arch. für Naturgesch., 51 (1), 235-255.

Maplestone (P. A.) et Badhuri (N. V.), 1942. - Helminths parasites of certain Rats in India. Rec. Indian. Mus., 44 (2), 201-206.

Mirza (M. B.) et Singh (S. N.), 1934. - Syphacia sciuri n. sp. a new oxyurid worm from Sciurus palmarum. Curr. Sc. Bangalore, 2, 345-346, fig. a-b.

Morgan (D. O.), 1932. - Oxyuris stroma Linstow, 1884. J. Helm., 10 (1), 15-20, fig. 1-6.

Petrov (A. M.) et Bayanov (M. G.), 1962. - Syphacia (Syphatineria) toshevi sp. n., nouveau Nématode de l'intestin de l'Ecureuil. Zool. Journ. Acad. Sc. U.R.S.S., 41 (7), 11021105 , figs.

Petter (A.-J.), 1966. - Equilibre des espèces dans les populations de Nématodes parasites du côlon des Tortues terrestres. Mém. Mus. Nat. Hist. Nat., sér. A, Zool., 34 (1), 1-252, fig. 1-96.

Price (E. W.), 1928. - Two new Nematode worms from Rodents. Proceed. Unit. St. Nat. Mus., 74 (4), 1-5, fig. 1-11.

Quentin (J.-C.), 1966. - Oxyures de Muridae africains. Ann. Parasit. Hum. Comp., 41 (5), 443-452, fig. 1-3.

-, 1968. - Description de Syphacia (Syphacia) alata n. sp. Oxyure parasite du Rongeur Cricetidae Zygodontomys lasiurus (Lund, 1839). Bull. Mus. Nat. Hist. Nat., $2^{\bullet}$ sér., 40 (4), 807-813, fig. 1-2.

-, 1969. - Etude de Nématodes Syphacia parasites de Rongeurs Cricetidae sud-américains et de leurs corrélations biogéographiques avec certaines espèces néarctiques. Bull. Mus. Nat. Hist. Nat., $2^{e}$ sér., 41 (4), 909-925, fig. 1-6. 
Roman (E.), 1945. - Spécificité parasitaire des Oxyuridés du genre Syphacia chez les Rats de l'Europe occidentale. Ann. Parasit. Hum. Comp., 20 (5-6), 297-298.

—, 1951. - Etude écologique et morphologique sur les Acanthocéphales et les Nématodes parasites des Rats de la région lyonnaise. Mém. Mus. Nat. Hist. Nat., sér. A, 2, 49-270, fig. $1-90+2 \mathrm{pl}$.

- et Pothier (M.-A.), 1968. - Oxyurose à Syphacia dans un élevage de Rats de laboratoire. Ann. Parasit. Hum. Comp., 43 (5), 597-603.

RUDOLPHI (C. A.), 1802. - Fortsetzung der Beobachtungen über Einge weide würmer. Arch. für. Zool. und Zoot., 2 (1), 1-67.

SANDGROUND (J. H.), 1933. - Reports on the scientific results of an expedition to the southwestern highlands of Tanganyika territory. VI. Parasitic Nematodes from east Africa and southern Rhodesia, Bull. Mus. Comp. Zool. Harvard college, 75 (6), 263-293, fig. 1-14.

Schmidt (G. D.) et KunTZ (R. E.), 1968. - Nematode parasites of Oceanica IV. Oxyurids of mammals of Palawan, P.I., with descriptions of four new species of Syphacia. Parasit., 58 (4), 845-854, fig. 1-16.

Seurat (L.-G.), 1915. - Sur deux nouveaux Oxyures du Maroc. Bull. Soc. Hist. Nat. Afr. N., 7 (2), 24-31, fig. 1-9.

—, 1916. - Sur les Oxyures des Mammifères. C.R. Soc. Biol. Paris, 79, 64-68, fig. 1-3.

SinHA (P. K.), 1960. - Syphacia srivastavi n. sp. from domestic pig in India. J. Parasit., 46 (4), 505-508, fig. 1-4.

Skrjabin (K. I.), Schikhobalova (N. B.) et Lagodovskaja (E. A.), 1960. - Osnovi Nematodologi. VIII. Oxyurata. Part. I, 557 p., 280 figs.

—, — et —, 1967. — Ibid. XVIII. Oxyurata. Part. V, 243 p., 133 figs.

Stammer (H. J.), 1955. - Die Parasiten deutscher Kleinsäuger. Verhand. der Deutsch. Zool. Gesellsch. in Erlangen, 361-390, fig. 1-10.

Tiner (J. D.), 1948. - Syphacia cu:amii n. sp. from the least chipmunk, Eutamias minimus, with a key to the genus (Nematoda, Oxyuridae). J. Parasit., 34 (2), 87-92, fig. 1-5.

- et Rausch (R.), 1949. - Syphacia thompsoni (Nematoda: Oxyuridae) from the Red Squirrel. Journ. Mam., 30 (2), 202-203.

- et - 1950. - Two New Syphacia (Nematoda: Oxyuridae) and observations on the Inner Circle Circumoral papillae in North American species of the genus. Nat. Hist. Miscellanea, 57, 1-6, fig. 1-12.

Travassos (L.), 1937. - Contribuiçao ao conhecimente da Phylogenia dos Oxyuridae (Nematoda). Mem. Inst. Oswaldo Ciuz, 32 (4), 607-613, pl. 1-6.

Yamaguti (S.), 1935. - Studies of the Helminth Fauna of Japan. Part. 13. Mammalian Nematodes. Jap. Journ. Zool., 6 (2), 433-457, fig. 1-28.

-, 1941. - Studies on the Helminth Fauna of Japan. Part. 35. Mammalian Nematodes II. Jap. Jou:n. Zool., 9 (3), 409-439.

-, 1943. - Studies on the Helminth Fauna of Japan. Part. 43. Mammalian Nematodes IV. Jap. Jouin. Zool., 10 (3), 427-454, fig. 1-34. 